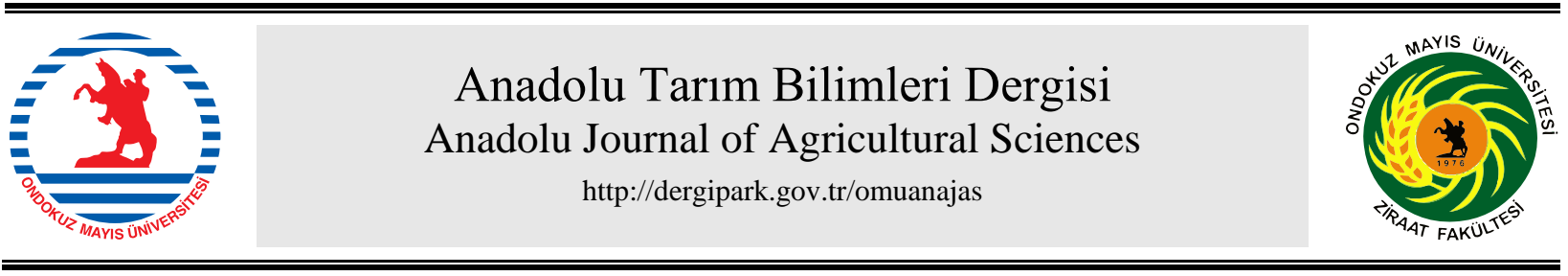

\title{
Araştırma/Research
}

Anadolu Tarım Bilim. Derg./Anadolu J Agr Sci, 34 (2019)

ISSN: $1308-8750$ (Print) 1308-8769 (Online) doi: $10.7161 /$ omuanajas. 441274

\section{Ordu ilinde sert çekirdekli meyve ağaçlarında bulunan akar türleri ${ }^{1}$}

\author{
Yunus Emre Altunç*, Rana Akyazı \\ Ordu Üniversitesi Ziraat Fakültesi Bitki Koruma Bölümü, 52200, Ordu \\ *Sorumlu yazar/Corresponding author: yunusemre_altunc@hotmail.com \\ Geliş/Received 06/07/2018 Kabul/Accepted 05. 02.2019
}

\begin{abstract}
ÖZET
Bu çalışma, 2016-2017 yılları arasında, iki vejetasyon dönemi boyunca, Ordu ilinin, Altınordu, Akkuş, Ünye, Fatsa, Ulubey, Kumru, Perşembe, Gülyalı, Kabadüz, Çaybaş1 ve İkizce ilçelerinde yürütülmüştür. Çalışmada bu bölgede yetiştirilen sert çekirdekli meyve ağaçlarında bulunan akar türleri araştırılmıştır. Örneklemeler, erik (Prunus domestica L.), kiraz (Prunus avium L.), vişne (Prunus cerasus L.), şeftali (Prunus persica L. Batsch) (Rosaceae) ve kızılcık (Cornus mas L. (Cornaceae)) olmak üzere 5 farklı meyve türünde yürütülmüştür. Çalışma süresince, toplam 176 mahallede, 474 adet örnekleme yapılmıştır. Örneklemeler her yılın mayıs, kasım ayları arasında, aylık periyotlarla gerçekleştirilmiştir. Çalışmalar süresince, 3 takıma bağlı 11 familyadan toplam 36 tür tespit edilmiştir. Bunlar içerisinde en yoğun bulunan familyalar Tetranychidae ve Phytoseiidae olmuştur. Bölgede, sert çekirdekli meyvelerde tetranychid akarlardan en çok Tetranychus urticae (Koch) ve Amphytetranychus viennensis (Zacher) (Trombidiformes: Tetranychidae) türleri tespit edilmişken, en baskın phytoseiid türler olarak Transeius wainsteini (Gomelauri) ve Phytoseiulus finitimus (Ribaga) (Mesostigmata: Phytoseiidae) belirlenmiştir.
\end{abstract}

Anahtar Sözcükler:

Akar

Fauna

Ordu

Sert çekirdekli meyve

\section{Mite species on stone fruit trees in Ordu province}

\section{ABSTRACT}

This study was conducted in Altınordu, Akkuş, Ünye, Fatsa, Ulubey, Kumru, Perşembe, Gülyalı, Keywords:

Kabadüz, Çaybaşı and İkizce districts of Ordu province during two vegetation periods between 2016- Fauna

2017. In the research, mite species on stone fruit trees were invesitigated. The samplings were carried out Mite

on 5 different fruit species; plum (Prunus domestica L.), cherry (Prunus avium L.), sour cherry (Prunus Ordu

cerasus L.), peach (Prunus persica L. Batsch) (Rosaceae) and cranberry [Cornus mas L. (Cornaceae)]. Stone fruit

During the study, a total of 474 samples were collected from 176 villages. Surveys were carried out monthly between May and November months of each year. During the study, 36 species belonging to1 1 families from 3 orders were identified. Among them, Tetranychidae and Phytoseiidae were the most common families. While Tetranychus urticae (Koch) and Amphytetranychus viennensis (Zacher) (Trombidiformes: Tetranychidae) were the most detected tetranychid mite species, Transeius wainsteini (Gomelauri) and Phytoseiulus finitimus (Ribaga) (Mesostigmata: Phytoseiidae) were the most dominant phytoseiid mite species on stone fruit trees in the region.

(C) OMU ANAJAS 2019

\section{Giriş}

Sert çekirdekli meyveler taksonomik olarak Rosales takımı, Rosaceae (gülgiller) familyası, Prunoideae alt familyası içerisinde yer alırlar (Özçağıran ve ark., 2003). Dünyada 5554723 hektar alanda, y1lda 45287496 ton, sert çekirdekli meyve üretimi yapılmaktadır (FAO, 2016). Türkiye de ise toplam 293761 hektarlık alandaki yıllık sert çekirdekli meyve üretimi 2894126 ton kadardır. Araştırmanın yapıldı ğı, Karadeniz Bölgesi'nin sahil şehri olan Ordu ilinde ise, sert çekirdekli meyvelerdendaha çok erik (1.608 ton), kiraz (986 ton), kızılcık (163 ton), vişne (27 ton) ve şeftali (14 ton) meyvelerinin yetiştiriciliği yapılmaktadır (TÜİK, 2017).

Sert çekirdekli meyvelerin ülkemiz ekonomisindeki rolü büyüktür. Türkiye' de 2017 y1lında toplam 296 milyon dolarlık sert çekirdekli meyve ihracatı yapılmıştır (Anonim 2018a). Ayrica sofralık, taze ve kuru 
tüketimlerinin yanı sıra gıda sanayii ve kozmetik sanayiinde önemli yere sahiplerdir (Anonim, 2012).

Ancak ülke ekonomisine bu denli faydaları olan sert çekirdekli meyvelerin yetiştiriciliğinde ekonomik kayıplara neden olan birçok hastalık zararlı ve yabancı otlar bulunmaktadır (Çobanoğlu ve Düzgüneş, 1986; Akbolat ve ark., 2006; Deligöz ve ark., 2015).

Meyvecilikte ekonomik kayılara neden olan zararlılar arasında akarların payı büyüktür. Dünyada sert çekirdekli meyve ağaçlarında bulunan akarlar üzerine yapılmış çalışmalar bulunmaktadır. Bunlardan, Boczek, (1964), Polonya'da kızılcık, Shinkaji, (1979), Japonya'da kiraz, De Lillo, (1997), İtalya'da kızılcık, Smith Meyer ve Craemer, (1999), Güney Afrika'da erik, kayıs1, kiraz ve mahlep, Ripka ve ark., (2002), Macaristan'da erik, çakal eriği, vişne, mahlep, Stojnic ve ark., (2002), Sirbistan ve Karadağ'da erik, Eichelberger ve ark., (2011) ile Montes ve ark., (2011), Brezilya'da şeftali, Riahi ve ark., (2011), İran'da şeftali, Bohinc ve Trdan, (2012), Slovenya'da erik, kiraz, şeftali, Li ve ark., (2012), Çin'de kayısı, Mladenovic ve ark., (2013), Surbistan'da erik, kiraz, vişne ve Baldo ve ark., (2016), Brezilya'da nektarin ağaçlarından çeşitli akar türleri tespit etmişlerdir.

Türkiye'de de sert çekirdekli meyve ağaçlarında bulunan akar faunasına dair pek çok araştırma yapılmış olup, bunlardan bazıları şu şekildedir; Kılıç ve Aykaç, (1989), Samsun, Amasya ve Tokat'da şeftali ağaçlarında, Ulusoy ve ark., (1999), Niğde ve Adana yöresi kiraz ağaçlarında, Öztürk ve Ulusoy, (2003), Mersin ili kayısı ağaçlarında, Bulut ve Madanlar, (2005), İzmir'de erik, kayısı, kiraz, vişne ve şeftali meyvelerinde, Özkan ve ark., (2005), Ankara'da vişne ağaçlarında, Ertop, (2006), Çanakkale ilinde kiraz bahçelerinde, Özcan, (2007), Konya'da kiraz ağaçlarında, Çobanoğlu, (2008), Malatya, Elazığ ve İzmir illerinde depolanmış kayısı meyvelerinde, Güven, (2008) İzmir ili şeftali bahçelerinde, Ertop ve Özpınar, (2011), Çanakkale ili kiraz ağaçlarında, Hazır ve Ulusoy, (2012), Adana ve Mersin illeri şeftali ve nektarin alanlarında Erdoğan, (2013), Tokat yöresi sert çekirdekli meyve ağaçlarında, Geçer ve Denizhan, (2015), Diyarbakır ili erik, kayısı, şeftali, kiraz ağaçlarında bulunan faydalı ve zararlı akar faunasının tespiti üzerine çalışmalar yapmışlardır.

Ancak, bugüne kadar Ordu ilinde sert çekirdekli meyvelerdeki akar türlerine yönelik yapılmış herhangi bir araştırma tespit edilememiştir. Bu nedenle ele alınan bu çalışma ile 2016 - 2017 yılları arasında, Ordu ilinin, Altınordu, Akkuş, Ünye, Fatsa, Ulubey, Kumru, Perşembe, Gülyalı, Kabadüz, Çaybaşı ve İkizce ilçelerinde, erik, kiraz, vişne, şeftali ve kızılcık yetiştiricilik alanlarında bulunan akar türlerinin tespiti hedeflenmiştir.

\section{Materyal ve Yöntem}

\subsection{Materyal}

Bu çalışma, 2016 (Mayıs) ve 2017 (Kasım) yılları arasında, 2 vejetasyon dönemi süresince, Ordu ili Merkez (Altınordu), Akkuş, Çaybaşı, Fatsa, Gülyalı, İkizce, Kabadüz, Perşembe, Ulubey, Ünye ve Kamru olmak üzere toplam 11 ilçede yürütülmüştür (Şekil 1). Araştırmanın ana materyalini bu yörede bulunan sert çekirdekli meyvelerden yörede en çok üretime sahip olan, erik (Prunus domestica L.), kiraz (Prunus avium L.), vişne (Prunus cerasus L.), şeftali (Prunus persica L. Batsch) (Rosaceae) ve kızılcık (Cornus mas L. (Cornaceae)) ağaçları ile onlardan elde edilen akar türleri oluşturmuş̧ur. Ordu ilinde toplam 176 mahallede, 382 farklı noktadan, 474 örnekleme yapılmıştır.

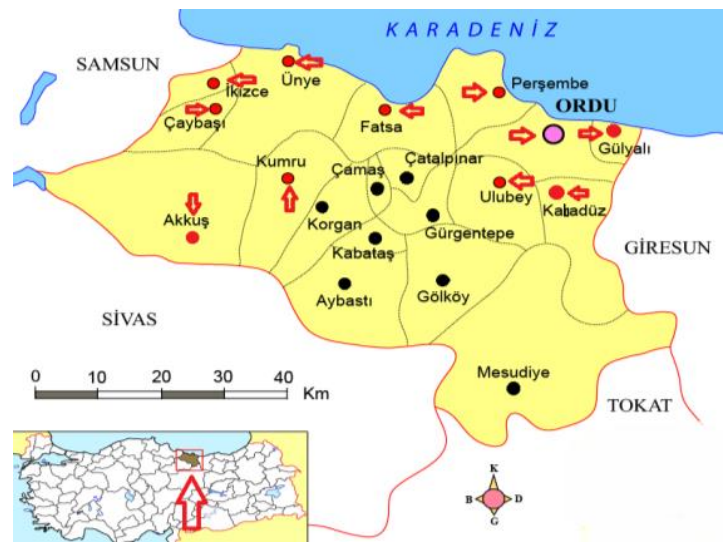

Şekil 1. Ordu ilinde örnekleme yapılan ilçeler

\subsection{Yöntem}

\subsubsection{Sörvey Çalışmaları}

Örneklemeler her yılın mayıs-kasım ayları arasında, aylık periyotlarla yapılmıştır. Örneklemeler bölgeleri temsil edecek şekilde ve farklı yüksekliklerde bulunan ağaçlardan yapılmıştır. Sörveyler esnasında yaprak örnekleri her ağaçtan 20 adet olacak şekilde ağaçların farklı yönlerinden, iç, dış, orta, alt ve üst kısımlarından rastgele toplanmıştır (Toros, 1974; Madanlar ve Kısmalı, 1991). Bahçelerde, örnekleme yapılacak olan ağaç sayısı ise, bahçedeki toplam ağaç sayısına göre belirlenmiştir. $\mathrm{Bu}$ amaçla Madanlar ve Kısmalı (1991)'nın sıkalası aynen uygulanmıştır (Çizelge 1).

Çizelge 1. Her bahçedeki toplam ağaç sayısına göre, örnek alınacak ağaç sayısı (Madanlar ve Kısmalı, 1991)

\begin{tabular}{ll}
\hline $\begin{array}{l}\text { Bahçedeki } \\
\text { ağaç sayıs1 }\end{array}$ & Örnek alınan ağaç sayısı \\
\hline $0-50$ & Tüm ağaçlardan \\
$51-200$ & 50 Ağaçtan \\
$201-400$ & $\begin{array}{l}\text { 60 Ağaçtan } \\
\text { Toplam ağaç sayısının \%10'u kadar } \\
\text { 400 den fazla } \\
\text { ağaçtan }\end{array}$ \\
\hline
\end{tabular}

Ordu ilinde sert çekirdekli meyvelerin kapama bahçe 
yetiştiriciliği az olduğundan örneklemelerde genellikle uygun olan her ağaçtan yaprak örneği alınmıştır. Alınan yaprak örnekleri, ayn yöne bakacak şekilde düzgünce istiflenerek, ambalaj kağıtlarına yerleştirildikten sonra, polietilen torbalara konulmuştur. Etiket bilgileri de yazılmış olan örnekler incelemeler süresince $+4{ }^{\circ} \mathrm{C}$ ' de ki buzdolabında saklanmıştır.

\subsubsection{Akarların toplanması ve preparasyon işlemleri}

Yaprak örnekleri üzerinde bulunan akarlar, stereomikroskop (Leica S8 APO) altında 000 no'lu samur firça veya ok uçlu iğne yardımı ile toplanmıştır (Ecevit, 1976). İncelenen yapraklardaki akarların gözden kaçabilme ihtimaline karşın, elle toplama işleminin ardından, örnekler Berlese Hunisine de konularak üzerlerinde bulunan tüm akarların elde edilmesi sağlanmıştır. Toplanan akarlar \%70'lik etil alkol içinde saklanmıştır (Ecevit, 1976; Krantz ve Walter, 2009). Eriophyoid akarlar dışında elde edilen diğer akar türlerinin berraklaştırılmalarında "lakto-fenol", preparat yapımında ise "hoyer" ortamı kullanılmıştır (Ecevit, 1976; Krantz ve Walter, 2009). Eriophyoid akarlar ise, Keifer' in "booster" ortamı içinde berraklaştırılmış ve "F" ortamı kullanılarak preparatları yapılmıştır (Amrine ve Manson, 1996).

\subsubsection{Teşhis çalışmaları}

Teşhis çalışmaları, faz kontrast mikroskop (Leica DM2500) kullanılarak gerçekleştirilmiştir. Tetranychidae familyası türleri için; Pritchard ve Baker, (1955), Zhang ve ark., (2002), Zhang, (2003), Seeman ve Beard, (2011), Ueckermann ve Çobanoğlu, (2012), Auger ve ark., (2013), Eriophyoidae üst familyası akarları için; Amrine ve ark., (2003), tenuipalpid türler için; Çobanoğlu ve ark., (2016), Ueckermann ve Çobanoğlu, (2012), Edward ve Donald, (1987), Cunaxidae familyasinda; Skvarla ve ark., (2014), Stigmaeidae familyası türleri için; Gonzalez, (1965), Fan ve Zhang, (2005), Tydeoidae üst familyasında; Ueckermann, (2013), Ripka ve ark., (2013), Phytoseiidae familyası türleri için; Muma ve Denmark, (1970), Rowell ve ark., (1978), Çobanoğlu (1989a), (1989b), (1989c), (1993a), (1993b), (1993c), (1993d), Faraji ve ark., (2007), Faraji ve ark., (2011) ve Winterschmidtiidae familyası için ise Solarz, (2012), tür teşhis çalışmalarında yararlanılan kaynaklardan bazılarıdır.

Yapılan tür teşhisleri uzman kişiler tarafından doğrulanmıştır (Çizelge 2). Teşhisli türler, Ordu Üniversitesi, Ziraat Fakültesi, Bitki Koruma Bölümü, Akaroloji laboratuvarı kolleksiyonunda saklanmaktadır.

\section{Bulgular ve Tartışma}

Çalışma boyunca 2016 ve 2017 yılları arasında Ordu ilinde toplam 11 ilçe de sert çekirdekli meyve ağaçlarında yapılan örneklemeler sonucunda 3 takıma bağlı 11 familyadan, toplam 36 farklı akar türü tespit edilmiştir (Çizelge 3).

\subsection{Tetranychidae Familyasindan Belirlenen Akar Türleri}

\subsubsection{Amphitetranychus viennensis (Zacher)}

Yayılışı ve konukçuları: Dünya'da Çin, Ermenistan, Gürcistan, Macaristan, Litvanya, Moldova, Portekiz ve Hollanda gibi 20'den fazla ülkede yayılım göstermektedir (Migeon ve ark., 2011).

Çizelge 2. Teşhis doğrulamalarını gerçekleştiren taksonomistler

\begin{tabular}{lll}
\hline Uzman & Üniversite & Akar Familyaları \\
\hline $\begin{array}{l}\text { Prof. Dr. Sultan } \\
\text { Çobanoğlu }\end{array}$ & $\begin{array}{l}\text { Ankara Üniversitesi, Ziraat Fakültesi, Bitki Koruma Bölümü, } \\
\text { Türkiye }\end{array}$ & Phytoseiidae \\
\hline $\begin{array}{l}\text { Prof. Dr. Eddie A. } \\
\text { Uckermann }\end{array}$ & $\begin{array}{l}\text { North-West University, Potchefstroom Campus, Unit for } \\
\text { Environmental Sciences and Management, South Africa }\end{array}$ & $\begin{array}{l}\text { Stigmaeidae, } \\
\text { Tydeidae, } \\
\text { Iolinidae, } \\
\text { Triophtydeidae } \\
\text { Tenuipalpidae }\end{array}$ \\
\hline Prof. Dr. Noeli J. Ferla & $\begin{array}{l}\text { Universidade do Vale do Taquari Univates, Laboratorio de } \\
\text { Acarologia, Technovates, Brazil }\end{array}$ & Cunaxidae \\
\hline $\begin{array}{l}\text { Dr. Mariusz } \\
\text { Lewandowsk1 }\end{array}$ & $\begin{array}{l}\text { Warsaw Univesity of Life Sciences, Faculty of Horticulture, } \\
\text { Biotechnology and Landscape Architecture Department of } \\
\text { Applied Entomology, Poland }\end{array}$ & $\begin{array}{l}\text { Eriophyidae, } \\
\text { Diptilomiopidae }\end{array}$ \\
\hline Dr. Philippe Auger & French National Institute for Agricultural Research, France & Tetranychidae \\
\hline Dr. Pavel B. Klımov & $\begin{array}{l}\text { University of Michigan, Department of Ecology and } \\
\text { Evolutionary Biology, USA }\end{array}$ & Winterschmidtiidae \\
\hline
\end{tabular}

Türkiye'de sert çekirdekli meyvelerden, Marmara bölgesinde (İstanbul, Kocaeli, Sakarya, Bolu, Gölcük, Edirne) şeftali, kiraz, erik, vişne ve mahlep üzerinde
(Göksu, 1968), Niğde ve Adana' da kirazda (Ulusoy ve ark., 1999), Bursa'da erik, kirazve vişnede (Kumral ve Kovanc1, 2007), Samsun'da erik, kiraz ve vişnede (İnal, 
2005), Çanakkale'de kiraz (Ertop, 2006), erik, kiraz, vişne, şeftali, mahlep ve kayısıda (Erdoğan, 2013) tespit edilmiştir.

Tür, birçok ilde sert çekirdeklilerin dışında farklı konukçular üzerinde de belirlenmiştir (Özman ve Çobanoğlu, 2001; İncekulak ve Ecevit, 2002; Yanar ve Ecevit, 2005; Çetin ve ark., 2006; Kasap ve Çobanoğlu, 2007; Elma ve Alaoğlu, 2008; Göven ve ark., 2009; Özsayın, 2012; Çobanoğlu ve Kumral, 2014; Kumral ve Çobanoğlu, 2015a, b; İnak ve Çobanoğlu, 2018).

A. viennensis bu çalışmada, erik, kiraz, şeftali ve vişne ağaçlarından toplanmıştır.

İncelenen materyal: Çaybaşı, 11.08.2016, $P$. domestica (1 O), P. avium (1 đ̊), Fatsa, 14.06.2016, $P$.

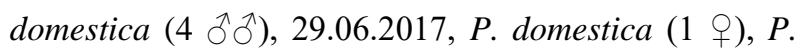
avium (1 9 ), P. persica (1 9 ), Gülyalı, 29.06.2016, P. domestica (2 우), 02.08.2016, P. avium (1 đ̊),İkizce, 11.08.2016, P. domestica (1 đ), Kumru, 28.07.2016, P. persica (1 đ̊), P. cerasus (1 †), Kabadüz, 09.08.2016, $P$.

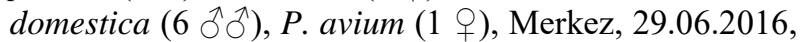

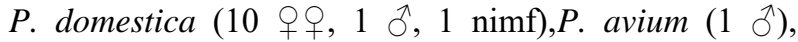
Perşembe, 21.06.2016, $P$. domestica (5 $ᄋ$ ㅇ, 1 đ), $P$. avium (2 우, 1 đ), $P$. cerasus (2 우), 21.07.2017, $P$. cerasus (2 우, 1nimf), Ulubey, 20.09.2016, $P$.

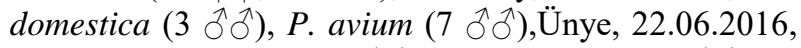

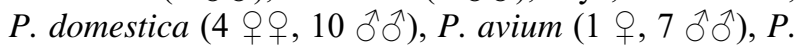
persica (1 ㅇ, 1 đ) $), 21.07 .2017$, P. domestica $(5$ 우 0,4 ふ઼े).

Çizelge 3. Ordu ilinde sert çekirdekli meyvelerde tespit edilen akar türleri

\begin{tabular}{|c|c|c|c|c|c|c|}
\hline Üst Takım & Takım & Familya & Tür & $q$ & $\sigma^{\pi}$ & $\mathrm{N}$ \\
\hline \multirow{21}{*}{ Acariformes } & \multirow{20}{*}{ Trombidiformes } & \multirow{6}{*}{ Tetranychidae } & Amphytetranychus viennensis & 43 & 53 & 2 \\
\hline & & & Briobia rubrioculus & 83 & - & - \\
\hline & & & Eotetranychus uncatus & - & 2 & - \\
\hline & & & $\overline{\text { Panonychus citri }}$ & 1 & - & - \\
\hline & & & Panonychus ulmi & 14 & 13 & - \\
\hline & & & Tetranychus urticae & 40 & 97 & 6 \\
\hline & & \multirow{2}{*}{ Tenuipalpidae } & Brevipalpus obovatus & 2 & - & - \\
\hline & & & Cenopalpus pulcher & 17 & - & 3 \\
\hline & & Eriophyidae & Aculus fockeui & 6 & - & - \\
\hline & & \multirow{2}{*}{ Diptilomiopidae } & Diptacus gigantorhynchus & 9 & - & - \\
\hline & & & Rhynophytoptus dudichi & 36 & - & - \\
\hline & & Cunaxidae & Cunaxoides lootsii & 5 & - & - \\
\hline & & \multirow{2}{*}{ Stigmaeidae } & Agistemus sp. & 1 & - & - \\
\hline & & & $\overline{\text { Zetzellia mali }}$ & 3 & - & - \\
\hline & & \multirow{2}{*}{ Iolinidae } & Homeopronematus sp. & 21 & - & - \\
\hline & & & Pronematus sp. & 2 & & \\
\hline & & Triophtydeidae & Triophtydeus triophthalmus & 80 & - & - \\
\hline & & \multirow{3}{*}{ Tydeidae } & Brachytydeus paraobliqua & 26 & - & - \\
\hline & & & Tydeus californicus & 132 & - & - \\
\hline & & & Tydeus goetzi & 105 & - & - \\
\hline & Sarcoptiformes & Winterschmidtiidae & Calvolia sp. & 142 & 3 & - \\
\hline \multirow{15}{*}{ Parasitiformes } & \multirow{15}{*}{ Mesostigmata } & \multirow{15}{*}{ Phytoseiidae } & Amblyseius andersoni & 15 & 8 & - \\
\hline & & & Amblyseius herbicolus & 3 & - & - \\
\hline & & & Aristadromips masseei & 1 & - & - \\
\hline & & & Euseius finlandicus & 44 & 2 & 1 \\
\hline & & & Galendromus longipilus & 6 & 1 & - \\
\hline & & & Neoseiulella tiliarum & 13 & 2 & - \\
\hline & & & Paraseiulus soleiger & 4 & - & - \\
\hline & & & Paraseiulus triporus & 2 & - & - \\
\hline & & & Phytoseiulus finitimus & 79 & 11 & 3 \\
\hline & & & Phytoseiulus persimilis & 1 & - & - \\
\hline & & & Phytoseius ribagai & 1 & - & - \\
\hline & & & Transeius wainsteini & 82 & 12 & 1 \\
\hline & & & Typhlodromus bakeri & 20 & - & - \\
\hline & & & Typhlodromus rhenanus & 3 & 2 & - \\
\hline & & & Typhlodromus tiliae & 1 & - & - \\
\hline Toplam & & & & 1043 & 206 & 16 \\
\hline \multicolumn{4}{|l|}{ Genel toplam } & \multicolumn{3}{|c|}{1265} \\
\hline
\end{tabular}




\subsubsection{Bryobia rubrioculus (Scheuten)}

Yayılışı ve konukçuları: Dünya da Afganistan, Kazakistan, Irak, Almanya, İtalya, Portekiz ve İngiltere gibi birçok ülkede yayılış göstermektedir (Migeon ve ark., 2011). Türkiye' de ise sert çekirdekli meyvelerden, Niğde ve Adana' da kiraz ağaçlarında (Ulusoy ve ark., 1999), Samsun'da erik ve kirazda (İnal, 2005), Bursa'da vişne ve erikte (Kumral ve Kovancı 2007), Çanakkale'de kirazda (Ertop, 2006) tespit edilmiştir. Bunların dışında tür, birçok ilde farklı konukçularda (Özman ve Çobanoğlu, 2001; İncekulak ve Ecevit, 2002; Yanar ve Ecevit, 2005; Kasap ve Çobanoğlu, 2007; Kumral ve Kovanc1, 2007; Güven, 2008; Güven ve Madanlar, 2011; Özsayın, 2012; Erdoğan, 2013; Kumral ve Çobanoğlu, 2015b; Çobanoğlu ve Güldalı, 2017) bulunmuştur.

Tür bu çalışmada, Ordu'da erik, kiraz, şeftali ve vişne ağaçlarında tespit edilmiştir.

İncelenen materyal: Akkuş, 05.08.2016, P. domestica (1 ㅇ), Fatsa, 14.06.2016, P. domestica (5우), P. persica (1ㅇ), P. avium (6 우), 29.06.2017, P. domestica (6 우으), Gülyal1, 02.08.2016, P. domestica (1 + ), İkizce, 11.08.2016, P. domestica (2 $\odot$ ), Kumru, 28.07.2016, $P$. domestica (1 ㅇ) ), 29.06.2017, P. domestica (4 우), P. cerasus (1 9 ), Kabadüz, 09.08.2016, P. domestica (3 우우), P. avium (2 우우), 21.07.2017, P. domestica (2 우우), Merkez, 29.06.2016, P. domestica (18 우), P. avium (1 †), 29.06.2017, P. domestica (1 †), Perşembe, 21.06.2016, P. domestica (2 우), 21.07.2017, P. domestica (2 + 9 ), Ulubey, 20.09.2016, P. domestica (3 우), P. avium (2 우), 29.06.2017, P. domestica (3 9 우), $P$. avium (2 + + ), Unnye, 22.06.2016, $P$. domestica $(9$ 우우), P. avium (5 우우).

\subsubsection{Eotetranychus uncatus Garman}

Yayılışı ve konukçuları: Dünya üzerinde Kanada, Meksika, Amerika Birleşik Devletleri, Paraguay, Hindistan, Çin, Fransa, İran, Japonya, Kazakistan, Hollanda ve Polonya'da, toplam 38 farklı konukçuda tespit edilmiştir (Migeon ve ark., 2011). Türkiye'de sert çekirdekli meyvelerden, şeftali erik ve mahlepte Tokat ilinde kayıtlanmıştır (Erdoğan, 2013). Tür, farklı illerden diğer konukçularda farklı araştırmacılar (Yanar ve Ecevit, 2005; Kasap ve Çobanoğlu, 2007; Kumral ve Çobanoğlu, 2015a,b; Çobanoğlu ve Kumral, 2014; Çobanoğlu ve Kumral, 2016) tarafindan da bulunmuştur.

E. uncatus, bu çalışmada kızılcık ağaçlarından elde edilmiştir. ふ).

İncelenen materyal: Akkuş, 05.08.2016, C. mas (3

\subsubsection{Panonychus citri (McGregor)}

Yayılışı ve konukçuları: Tür, Japonya, İsrail, Çin ve İtalya'nın arasında olduğu 69 ülkede 108 farklı konukçuda tespit edilmiştir (Migeon ve ark., 2011). Türkiye'de daha önce sert çekirdekli meyvelerin dışında farklı konukçularda da bulunmuştur (Düzgüneş, 1952; İnal, 2005; Satar ve ark., 2013).

$\mathrm{Bu}$ çalışma ile Ordu ilinde vişne ağacından elde edilmiştir.

İncelenen materyal: Ünye, 22.06.2016, P. cerasus (1 ㅇ).

\subsubsection{Panonychus ulmi (Koch)}

Yayılışı ve konukçuları: Dünya'da Norveç, Moldovya, Portekiz, İsviçre, Belçika, Mısır ve Ukrayna gibi birçok ülkede farklı konukçularda tespit edilmiştir (Migeon ve ark., 2011). Türkiye'de ise, Adana, Niğde (Ulusoy ve ark., 1999) ve Çanakkale'de (Ertop, 2006) kiraz, Samsun'da erik (İnal, 2005), Bursa'da kiraz, şeftali ve erik (Kumral ve Kovanc1, 2007), Tokat'da şeftali ve erikte (Erdoğan, 2013) bulunmuştur. Bunların dışında Türkiye' nin farklı illerinde birçok konukçuda pek çok araştırmacı (İncekulak ve Ecevit, 2002; Yanar ve Ecevit, 2005; Kasap ve Çobanoğlu, 2007; Satar ve ark., 2013; Gençer Gökçe, 2015) tarafından kayıtlanmıştır.

Bu çalışmada, Ordu ilinde de erik, kiraz ve şeftali yapraklarından elde edilmiştir.

İncelenen materyal: Fatsa, 14.06.2016, $P$. domestica

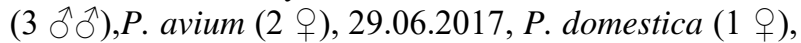
Gülyal1, 02.08.2016, P. avium (1 +),Kumru, 28.07.2016,

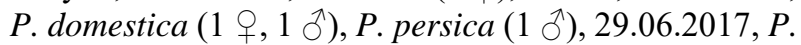
domestica (1 +), Kabadüz, 21.07.2017, P. domestica (1 P), Merkez, 29.06.2016, P. domestica (1 9$)$,

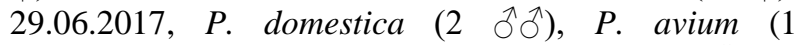
P),Perşembe, 21.06.2016, P. domestica (1 ९)), Ünye, 22.06.2016, P. domestica (1 +, 5 §ð), P. avium (1 P), 21.07.2017, P. domestica (2 우).

\subsubsection{Tetranychus urticae Koch}

Yayılış1 ve konukçuları: Dünya genelinde 124 ülkede 1140 farklı konukçu üzerinde tanımlanmış kozmopolit bir türdür (Migeon ve ark., 2011). Türkiye'de birçok ilde farklı konukçular üzerinde tespit edilmiştir (Ulusoy ve ark., 1999; Özman ve Çobanoğlu, 2001; İncekulak ve Ecevit, 2002; Yanar ve Ecevit, 2005; İnal, 2005; Cetin ve ark., 2006; Ertop 2006; Kumral ve Kovanc1, 2007; Kasap ve ark., 2008; Elma ve Alaoğlu, 2008; Güven 2008; Özsayın, 2012; Satar ve ark., 2013; Erdoğan, 2013; Çobanoğlu ve Kumral, 2014; Kumral ve Çobanoğlu, 2015a, b; Gençer Gökçe, 2015; Kutlu, 2016; Akyazı ve ark., 2017; Çobanoğlu ve Güldalı, 2017; Soysal ve Akyazı, 2018).

Bu çalışmada Ordu ilinde erik, kiraz, şeftali ve vişne ağaçlarından toplanmıştır.

İncelenen materyal: Çaybaşı, 11.08.2016, $P$. avium (1

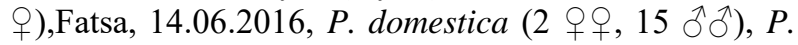

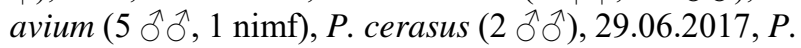
domestica (3우, 7 ๙, $1 \mathrm{n})$, P. avium (2 우), P. persica

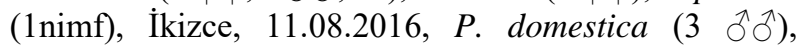
Kumru, 28.07.2016, P. domestica (1 3$)$, P. avium (3

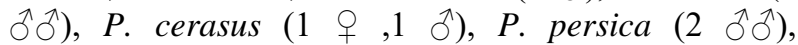


29.06.2017, P. domestica (1 ㅇ, 1 đ̋), P. cerasus (2 우

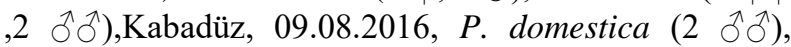
Merkez, 29.06.2016, P. domestica (9 우, 3ðぇ, 1n), $P$. avium (3 §), P. persica (1 §), 29.06.2017, P. domestica

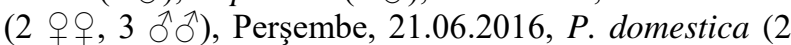

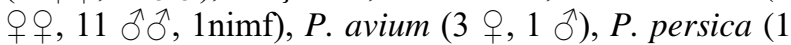
, 1 ○), P. cerasus (1 ㅇ), 21.07.2017, P. domestica (1

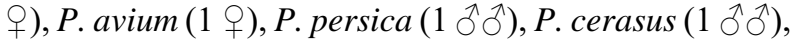
Ulubey, 20.09.2016, P. domestica (1 9 ), 29.06.2017, P.

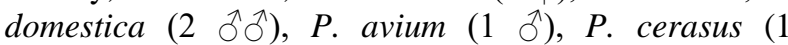

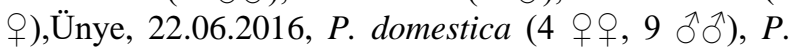

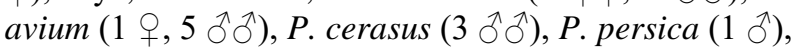
21.07.2017, P. domestica (2 ふぇ).

\subsection{Tenuipalpidae Familyasından Belirlenen Akar Türleri}

\subsubsection{Brevipalpus obovatus Dannadiperseu}

Yayılışı ve konukçuları: Dünya genelinde yayılım göstermektedir (Jeppson ve ark., 1975). Türkiye'de daha önce sert çekirdekli meyveler dişında farklı konukçularda (Düzgüneş, 1952; Önuçar ve Ulu, 1988; Özman Sullivan ve ark., 2007; Kasap ve ark., 2015; Soysal ve Akyazı, 2018; Akyazı ve ark., 2017) tespit edilmiştir.

Tür, bu çalışma da kızılcık yapraklarından toplanmıştır. 우)

İncelenen materyal: Ulubey, 20.09.2016, C. mas (2

\subsubsection{Cenopalpus pulcher (Canestrini and Fanzago)}

Yayılışı ve konukçuları: Dünyada, İngiltere, Hollanda, İtalya, Kıbrıs, İsrail, Misır, Afganistan, Gürcistan, İran, Avusturya, Portekiz, Bulgaristan ve Hollanda gibi birçok ülkede yayılış göstermektedir (Jeppson ve ark., 1975). Türkiye' de sert çekirdekli meyvelerden kiraz ve erikte, Ankara, Bursa, İzmir, Konya ve Niğde' de (Düzgüneş, 1965), erik ağaçlarında Ankara' da (Sağlam ve Çobanoğlu 2010), kiraz, vişne, şeftali, mahlep, erik (Erdoğan, 2013) ve kayısı (Erdoğan ve Yanar, 2015) yapraklarından Tokat' da toplanmıştır. Bunların dışında farklı illerde birçok konukçuda belirlenmiştir (Özman ve Çobanoğlu, 2001; İncekulak ve Ecevit, 2002;Akyazı ve Ecevit, 2003; Yanar ve Ecevit, 2005; Kasap ve Çobanoğlu 2007; Akyazı ve ark., 2017; İnak ve Çobanoğlu, 2018).

C. pulcher, Ordu ilinde erik, kiraz ve kızılcık meyvelerinde bulunmuştur.

İncelenen materyal: Akkuş, 05.08.2016, C. mas (4 우, 2nimf), P. domestica (2 우), P. avium (1nimf), Gülyal1, 02.08.2016, $P$. avium (7 + + $)$ ),Ulubey, 20.09.2016, P. domestica (1 †).

\subsection{Eriophyidae Familyasından Belirlenen Akar Türleri}

3.3.1. Aculus fockeui (Nalepa et Trqussart)
Yayılışı ve konukçuları: Dünya'da Danimarka, Letonya, Japonya, Hırvatistan, Çin, Şili, Portekiz ve İspanya gibi birçok ülkede yayılım göstermektedir (Denizhan ve Çobanoğlu, 2010). Türkiye'de ise Erzurum ve Erzincan illerimizde erik ve vişne ağaçlarında (Alaoğlu, 1984), Samsun'da erik, kiraz ve vişnede (İnal, 2005), Ankara'da vişne, mahlep ve kiraz eriği ağaçlarında (Denizhan, 2007), Van'da (Denizhan ve Çobanoğlu, 2010) şeftali, erik ve kirazda, Tokat'da (Erdoğan, 2013) kiraz, vişne, erik ve mahlep gibi sert çekirdekli meyvelerde ve Diyarbakır'da (Geçer ve Denizhan, 2015) erik, kiraz, şeftali ve vişne yapraklarından elde edilmiştir.

Bu çalışmada Ordu ilinin farklı ilçelerindeki kiraz ağaçlarından toplanmıştır.

İncelenen materyal: Fatsa, 14.06.2016, P. avium (4 우),Perşembe, 21.06.2016, P. avium (1 ㅇ),Ulubey, 20.09.2016, P. avium (1 ㅇ).

\subsection{Diptilomiopidae Familyasından Belirlenen Akar Türleri}

\subsubsection{Diptacus gigantorhynchus (Nalepa)}

Yayılışı ve konukçuları: Dünya'da Finlandiya, Polonya, Almanya, İtalya, Kanada, Çin ve Bulgaristan gibi birçok ülkede otuza yakın konukçuda tespit edilmiştir (Denizhan, 2007). Türkiye'de Erzincan ve Erzurum'da erik ve vişne ağaçlarında (Alaoğlu, 1984), Tokat'da kayısı, vişne ve erik yetiştiriciliği yapılan alanlarda (Erdoğan, 2013) bulunmuştur. Sert çekirdekli meyvelerin dışında farklı konukçularda da kaydı vardır (Denizhan, 2007; Geçer ve Denizhan, 2015).

D. gigantorhynchus, Ordu ilinde de erik, kiraz ve kızılcık ağaçlarından toplanmıştır.

Íncelenen materyal: Gülyal1, 02.08.2016, P. avium (1 )), İkizce, 11.08.2016, P. domestica (1 + ), Kabadüz, 09.08.2016, P. domestica (1 + ), Ulubey, 20.09.2016, P. domestica (3 9 + ), P. avium (1 $q), C$. mas (1 9$)$, Ünye, 22.06.2016, P. domestica (1 ㅇ).

\subsubsection{Rhinophytoptus dudichi Farkas}

Yayılışı ve konukçuları: Dünya'da Macaristan, Ermenistan ve Rusya'da erikte tespit edilmiştir. Türkiye'de Erzurum'da erik ağaçlarında (Alaoğlu, 1991) ve Tokat'ta erik üzerinde tespit edilmiştir (Erdoğan, 2013).

Ordu ilinde erik ve şeftali yapraklarından toplanmıştır.

Incelenen materyal: Fatsa, 14.06.2016, P. domestica (2 우), Gülyal1, 02.08.2016, P. domestica (4 우), P. persica (1 ㅇ), İkizce, 11.08.2016, P. domestica (2 $ᄋ$ ㅇ), Kabadüz, 09.08.2016, P. domestica (9 우), Merkez, 29.06.2016, P. domestica (6 우),Perşembe, 21.06.2016, P. domestica (1 +$),$ Ulubey, 29.06.2017, P. domestica (1 9 ), Ünye, 22.06.2016, P. domestica (6 9 . $)$, P. persica (2우우), 21.07.2017, P. domestica (2우우). 


\subsection{Cunaxidae Familyasından Belirlenen Akar Türleri}

\subsubsection{Cunaxoides lootsi Den Heyer}

Yayılışı ve habitatı: Dünyada İran'da (Heyer ve ark., 2013) tespit edilmiş olan bu tür, Türkiye'de Ordu ilinde bazı sebzelerde kayıtlanmıştır (Soysal, 2017). Bu çalışma da ise erik ve kirazda $T$. californicus, $T$. triophthalmus, Homeopronematus sp., A. viennensis, B. rubrioculus ve $B$. paraobliqua türleri ile birlikte bulunmuştur.

İncelenen materyal: Gülyalı, 02.08.2016, $P$. domestica (1 O), İkizce, 11.08.2016, P. domestica (1 ),Merkez, 29.06.2016, P. domestica (1 O),Ulubey, 20.09.2016, P. domestica (1 q), P. avium (1 ㅇ).

\subsection{Stigmaeidae Familyasından Belirlenen Akar Türleri}

\subsubsection{Agistemus sp. Summers}

Yayılışı ve habitatı: Dünya'da İran (Khanjani ve ark., 2015) ve Brezilya (Eichelberger ve ark., 2011; Baldo ve ark., 2016)'da bu cinse ait tüler bulunmuştur. Türkiye'de Agistemus cinsine ait farklı türler, birçok bitkide tespit edilmiştir (Özman ve Çobanoğlu, 2001; Gençer ve ark., 2005; Yeşilayer ve Çobanoğlu, 2011; Kasap ve ark., 2013).

Ordu ilinde yürütülen bu çalışmada tür, $T$. californicus ile birlikte erik ağacından toplanmıştır.

İncelenen materyal: Ünye, 22.06.2016, P. domestica (1 9 ).

\subsubsection{Zetzellia mali (Ewing)}

Yayılışı ve habitatı: Dünya'da Kanada, Fransa, Amerika Birleşik Devleti, İngiltere, İsviçre, İran ve Hollanda'da yayılım göstemektedir (Gonzalez, 1965; Gerson ve ark., 2003). Tür, daha önce sert çekirdekli meyvelerden erik ve kiraz ağaçlarında Bursa (Kumral ve Kovanc1, 2007) ve Tokat'da (Erdoğan, 2013) tespit edilmiştir. Türkiye'de farklı habitatlardan da elde edilmiştir (Düzgüneş, 1963; Akyazı ve Ecevit 2003; İnal, 2005; Kasap ve Çobanoğlu, 2007; Elma ve Alaoğlu, 2008; Kasap ve ark., 2008, 2013; Özsayın, 2012; Satar ve ark., 2013; Çobanoğlu ve Kumral, 2014; Kasap, 2014; Gençer Gökçe, 2015; Kumral ve Çobanoğlu, 2015a,b; Akyazı ve ark., 2017; Soysal ve Akyazı, 2018).

Ordu' da erik ve şeftali ağaçlarında Calvolia sp., $T$. triophthalmus ve $T$. urticae türleri ile birlikte toplanmıştır.

İncelenen materyal: Merkez, 29.06.2016, $P$. domestica (1 O), Ulubey, 20.09.2016, P. domestica (1 q),Ünye, 21.07.2017, P. persica (1 9 ).

\subsection{Iolinidae Familyasından Belirlenen Akar Türleri}

\subsubsection{Homeopronematus sp.}

Yayılışı ve habitatı: Homeopronematus cinsine ait türler dünyada Amerika Birleşik Devletleri (Knop ve Hoy, 1983; Hessein ve Perring, 1986), Macaristan (Ripka ve ark., 2013; Tempfli ve ark., 2015) ve Sirbistan (Stojnic ve ark., 2002)'da dağılım göstermektedir. Türkiye'de birçok ilde ve habitatlarda Homeopronematus cinsine ait farklı türler tespit edilmiştir (Özman-Sullivan ve ark., 2005; Tokkamış, 2011; Çobanoğlu ve Kumral, 2014; Kumral ve Çobanoğlu, 2015b; Kutlu, 2016; Akyazı ve ark., 2017; Soysal ve Akyazı, 2018).

$\mathrm{Bu}$ çalışmada ise cins düzeyinde teşhisi yapılabilen akar, erik ve kiraz ağaçlarından Calvolia sp., $P$. ulmi, $R$. dudcihi, A. viennensis, D. gigantorhynchus ve T.urticae ile birlikte toplanmıştır.

İncelenen materyal: Akkuş, 05.08.2016, P. domestica (1 O), Çaybaşı, 11.08.2016, P. domestica (1 O), Fatsa, 14.06.2016, P. domestica (5 우), Kumru, 28.07.2016, $P$. domestica (1 ㅇ), P. avium (1 ㅇ), Kabadüz, 09.08.2016, P. domestica (6 우), P. avium (1 ㅇ), Merkez, 29.06.2016, P. domestica (2 우), Perşembe, 21.06.2016, P. avium (1 ), Ünye, 22.06.2016, P. domestica (1 9 ).

\subsubsection{Pronematus sp.}

Yayılışı ve habitatı: Pronematus türleri dünyada Amerika Birleşik Devletleri (Knop ve Hoy, 1983), Brezilya (Eichelberger ve ark., 2011) ve Macaristan (Tempfli ve ark., 2015) gibi birçok ülkede belirlenmiştir. Türkiye'de ise bu cinse ait türler sert çekirdekli meyvelerden erik, kiraz ve şeftalide Bursa'da (Kumral ve Kovancı, 2007) ve şeftali ağaçlarında İzmir'de (Güven ve Madanlar, 2011) bulunmuştur. Tür, bunların dışında farklı illerde ve bitkilerde belirlenmiştir (ÖzmanSullivan ve ark., 2005; Tokkamış, 2011; Çobanoğlu ve Kumral, 2014; Kumral ve Çobanoğlu, 2015b; Kutlu, 2016; Akyazı ve ark., 2017; Soysal ve Akyazı, 2018).

Bu çalışma ile Ordu ilinde, erik ağaçlarında T. urticae ve $A$. viennensis ile birlikte elde edilmiştir.

Incelenen materyal: Fatsa, 14.06.2016, P. domestica (1 ㅇ) , Ulubey, 20.09.2016 P. domestica (1 ㅇ).

\subsection{Triophtydeidae Familyasından Belirlenen Akar Türleri}

\subsubsection{Triophtydeus triophthalmus (Oudemans)}

Yayılışı ve habitatı: Dünya'da Almanya, İsviçre, İtalya ve Macaristan'da bulunmuştur (Tempfli ve ark., 2015). Türkiye'de daha önce farklı habitatlarda tespit edilmiştir (Çobanoğlu ve Kazmierski, 1999; ÖzmanSullivan ve ark., 2005; Akyazı ve ark., 2017; Soysal ve Akyazı, 2018).

Tür, Ordu ilinde erik, kiraz, vişne, şeftali ve kızılcık ağaçlarında Calvolia sp., T. urticae, B. rubrioculus, $R$. $d u d c i h i$ ve $A$. viennensis, türleri ile beraber yoğun olarak elde edilmiştir.

İncelenen materyal: Akkuş, 05.08.2016, P. domestica

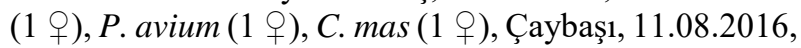
P. domestica (6 Oㅇ), Fatsa, 14.06.2016, P. domestica (7 우), P. cerasus (1 ㅇ), 29.06.2017, P. domestica (1 ㅇ), 
İkizce, 11.08.2016, P. domestica (4 우), P. avium (1 ㅇ), Kumru, 28.07.2016, P. domestica (7 9 ㅇ), P. avium (1 P), Kabadüz, 09.08.2016, P. domestica (8 9 + $)$ ), P. avium $(1$ $), 21.07 .2017$, P. domestica (3 o+ + ), Merkez, 29.06.2016, $P$. domestica (7 우), $P$. avium (1 9 ), Perşembe, 21.06.2016, P. domestica (8 우우), P. persica (2 우), 21.07.2017 P. domestica (2 우), Ulubey, 20.09.2016, P. domestica (3 9 우), Ünye, 22.06.2016, $P$. domestica (6 우), P. avium (1 ), 21.07.2017, $P$. domestica $(5$ 우우).

\subsection{Tydeidae Familyasından Belirlenen Akar Türleri}

\subsubsection{Brachytydeus paraobliqua Panou \& Emmanuel}

Yayılışı ve habitatı: Dünyada daha önce Yunanistan'da kiraz ve kızılcıkta (Panou ve Emmanouel, 1996), Macaristan'da 1hlamur (Ripka ve ark., 2002) ve bağlarda (Tempfli ve ark., 2015) tespit edilmiştir. Türkiye'de daha önce sert çekirdeklilerin dışında farklı konukçulardan (Özman-Sullivan ve ark., 2005; Akyazı ve ark., 2017) elde edilmiştir.

Bu çalışma ile Ordu'da erik, kiraz, kızılcık ve vişne meyvelerinde kayıtlanmıştır. Tür, meyve yapraklarından A. fockeui, R. dudcihi, Calvolia sp., B. rubrioculus ve A. viennensis akarları ile birlikte toplanmıştır.

İncelenen materyal: Çaybaşı, 11.08.2016, $P$. avium (1 ),Fatsa, 14.06.2016, P. domestica (2 우), P. avium (1 +), Gülyal1, 02.08.2016, P. domestica (3 우), C. mas (1 + ), İkizce, 11.08.2016, P. avium (1 + ), Kumru, 28.07.2016, P. domestica (1 +), Kabadüz, 09.08.2016, $P$. domestica (3 우), P. avium (1 ㅇ) , Merkez, 29.06.2016, P. domestica (1 P),29.06.2017, P. domestica (1 P), P. cerasus (1 + ), Perşembe, 21.06.2016, P. domestica (2 우), Ulubey, 20.09.2016, P. domestica (4 우우), P. avium $(1$ + $)$, Ünye, 22.06.2016, P. domestica (2 우).

\subsubsection{Tydeus californicus (Banks)}

Yayılışı ve habitatı: Dünyada, özelikle güney ülkelerde meyve, narenciye ve süs bitkilerinde oldukça yaygın dağılım göstemektedir (Tempfli ve ark., 2015). Türkiye'de sert çekirdekli meyvelerden erik ve kayısı (Çobanoğlu ve Kazmierski, 1999) bahçelerinde, Bursa da kiraz ve şeftaliağaçlarında (Kumral ve Kovancı, 2007), İzmir'de şeftali bahçelerinde (Güven, 2008), Tokat'da şeftali kiraz, erik, vişne ve mahlep yetiştirilen alanlarda (Erdoğan, 2013) tespit edilmiştir. Tür, diğer birçok ilde farklı bitkilerden de elde edilmiştir (Çobanoğlu, 19911992; Özman ve Çobanoğlu, 2001; İncekulak ve Ecevit, 2002; Akyazı ve Ecevit, 2003; Yanar ve Ecevit, 2005; Kasap ve Çobanoğlu, 2007; Kasap ve ark., 2008; Özsisli ve Çobanoğlu, 2011; Yeşilayer ve Çobanoğlu, 2011; Özsayın, 2012; Kasap ve ark., 2013; Satar ve ark., 2013; Kasap, 2014; Gençer Gökçe, 2015; Akyazı ve ark., 2017; Soysal ve Akyazı, 2018).

Bu çalışma ile Ordu ilinde erik, kiraz, şeftali, vişne ve kızılcık ağaçlarında, C. pulcher, Calvolia sp., B. rubrioculus, R. dudichi, P. ulmi, T. urticae, A. viennensis ve $A$. fockeui türleri ile birlikte toplanmıştır.

İncelenen materyal: Akkuş, 05.08.2016, P. domestica (7 우), P. avium (4 우), P. cerasus (2 우), C. mas (5 우), Çaybaş1, 11.08.2016, P. domestica (3 웅), P. avium (1 P), Fatsa, 14.06.2016, P. domestica (10 웅), P. persica (2 우), 29.06.2017, P. domestica (3 웅), Gülyal1, 02.08.2016, P. domestica (3 우), $P$. avium (2 우), P. persica (1 + $)$, İkizce, 11.08.2016, P. domestica (3 웅), Kumru, 28.07.2016, P. persica (1 ㅇ), P. cerasus (2 우), Kabadüz, 21.07.2017, P. domestica (1 + ), Merkez, 29.06.2016, P. domestica (6우), P. avium (10 우우), 29.06.2017, P. domestica (1 우), P. avium (3 우우), Perşembe, 21.06.2016, P. domestica (5웅), P. avium (8 웅), P. persica (3 웅), P. cerasus (4 우우), 21.07.2017, $P$. domestica (2우), P. persica (4 웅), Ulubey, 20.09.2016, $P$. cerasus (1 9 ), Ünye, 22.06.2016, $P$. domestica (18 우), P. avium (14 우우), P. cerasus (2 우우), 21.07.2017, P. domestica (1 ㅇ).

\subsubsection{Tydeus goetzi Schruft}

Yayılışı ve habitatı: Dünya'da Almanya ve Fransa'da tespit edilmiştir. Türkiye'de ise daha önce Ordu ilinde Trabzon hurması yapraklarında bulunmuştur (Akyazı ve ark., 2017).

$\mathrm{Bu}$ çalışmada erik, kiraz, şeftali, vişne ve kızılcık yapraklarından E. uncatus, T. urticae, Calvolia sp., $C$. pulcher, R. dudichi, P. ulmi, B. rubrioculus, A. viennensis ve $A$. fockeui türleri ile birlikte toplanmıştır.

İncelenen materyal: Akkuş, 05.08.2016, $P$. domestica (3 9 ), Fatsa, 29.06.2017, P. domestica (1 + ), Gülyal1, 02.08.2016, $P$. domestica (9 우), $P$. avium (7 우우), $P$. persica (3 우우), C. mas (4 우), İkizce, 11.08.2016, $P$. domestica (1 +), Kumru, 28.07.2016, P. domestica (1 )), Merkez, 29.06.2016, P. domestica (19 우 ㅇ), P. avium (15 우우), P. persica (1 우), 07.06.2016, P. cerasus (5 웅), 29.06.2017, P. domestica (6 우), Perşembe, 21.06.2016, P. domestica (14 우우), $P$. avium (3 우우), $P$. persica (3 우), 21.07.2017, P. domestica (1 ㅇ), P. persica (1 +), Ulubey, 29.06.2017, P. domestica (1 P), Ünye, 22.06.2016, $P$. domestica (2 + + $), P$. avium (1 + ), 21.07.2017, P. domestica (1 $\odot$ ).

\subsection{Winterschmidtiidae Familyasindan Belirlenen Akar Türleri}

\subsubsection{Calvolia sp. Oudemans}

Yayılışı ve habitatı: Dünya'da, Bangladeş (Gupta ve Sanyal, 2004), Amerika Birleşik Devletleri, Polonya ve Ukrayna'da (Krantz ve Walter, 2009) tespit edilmiştir. Bu cins Türkiye'de daha önce Ordu ilinde sebzelerde kayıtlanmıştır (Soysal ve Akyazı, 2018).

Bu çalışma ile Ordu'da erik, kiraz, vişne, şeftali ve kızılcık ağaçlarından yoğun olarak toplanmıştır.

İncelenen materyal: Akkuş, 05.08.2016, $P$. domestica (8 우), P. avium (3 우), P. cerasus (2 우), C. mas (4 우), Çaybaşı, 11.08.2016, P. domestica (10 우), $P$. avium (1 +), Fatsa, 14.06.2016, P. domestica (1 + ), 
29.06.2017, P. domestica (2 우), P. persica (1 + ), Gülyal1, 02.08.2016, P. domestica (10 우), P. avium (5 우), P. persica (1 우), C. mas (2 우), İkizce, 11.08.2016, P. domestica (3 우), Kumru, 28.07.2016, P. domestica (6 qㅇ), P. avium (3 우), P. persica (1 P), 29.06.2017, P. domestica (1 + ), P. avium (1 + ), Kabadüz, 09.08.2016, P. domestica (10 우), P. avium (7 웅), Merkez, 29.06.2016, $P$. domestica (10 우), $P$. avium (4 우), 29.06.2017, $P$. domestica (3 웅), Perşembe, 21.06.2016, P. domestica (4 우 (2 웅), 21.07.2017, P. domestica (1 ㅇ), Ulubey, 20.09.2016, P. domestica (5 우), P. avium (1 ㅇ), C. mas (1 + ), 29.06.2017, $P$. domestica (6 $q$ \%), Ünye, 22.06.2016, P. domestica (13 우), 21.07.2017, P. domestica $\left(9\right.$ 우, $\left.3 \stackrel{\bigcirc}{{ }^{\top}}\right)$.

\subsection{Phytoseiidae Familyasindan Belirlenen Akar Türleri}

\subsubsection{Amblyseius andersoni (Chant)}

Yayılışı ve habitatı: Dünyada Azerbaycan, Fransa, Yunanistan, İtalya, Amerika Birleşik Devletleri, Suriye, Sırbistan, Moldova gibi otuzdan fazla ülkede yayılış göstermektedir (Demite ve ark., 2014). Türkiye'de, Tokat ilinde sert çekirdekli meyvelerden erik, kiraz, vişne, şeftali, kayısı ve mahlepte (Erdoğan, 2013), Samsun'da ise erik (İnal, 2005) ağaçlarında bulunmuştur. Tür, farklı habitatlarda diğer bazı illerde de farklı araştırmacılar tarafından (Çobanoğlu, 1993b; Akyazı ve Ecevit, 2003, 2005; Çobanoğlu, 2004;İnal, 2005; Bayram ve Çobanoğlu, 2007; Yanar ve Ecevit, 2005; Kumral ve Kovanc1, 2007; Özsisli ve Çobanoğlu, 2011; Yeşilayer ve Çobanoğlu, 2011; Faraji ve ark., 2011; Özsayın, 2012; Satar ve ark., 2013; Kasap ve ark., 2013; Gençer Gökçe, 2015; Kumral ve Çobanoğlu, 2015a, b; Çobanoğlu ve Kumral, 2016; Çobanoğlu ve Güldalı, 2017; Akyazı ve ark., 2017; Soysal ve Akyazı, 2018) kayıtlanmıştır.

Ordu'da sert çekirdekli meyvelerden, erik, kiraz ve șeftali ağaçlarında, A. viennensis, T. urticae, Homeopronematus sp., B. rubrioculus, $R$. dudicihi, Calvolia sp., B. paraobliqua, T. goetzi, T. californicus ve A. fockeui türleri ile birlikte elde edilmiştir.

İncelenen materyal: Çaybaşı, 11.08.2016, P. avium (1

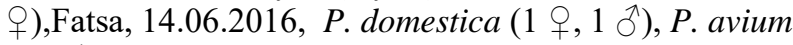
$\left(\begin{array}{ll}1 & 0\end{array}\right), 29.06 .2017$, P. domestica (1 + $)$, Gülyalı, 02.08.2016, P. domestica (1 +), P. avium (1 9$)$, Kumru,

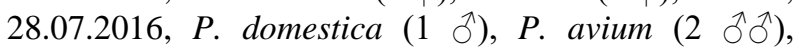
Kabadüz, 09.08.2016, $P$. avium (1 đ), Merkez, 07.06.2016, P. domestica (1 ㅇ), P. avium (4 우), 29.06.2017, P. domestica (1 9$), P$. avium (1 9 ), Perşembe, 21.06.2016, P. avium (1 +, 1 ठ), P. persica (2 9 ㅇ), Ünye, 22.06.2016, $P$. persica (1 ㅇ).

\subsubsection{Amblyseius herbicolus Chant}

Yayılış1 ve habitatı: Dünya üzerinde Brezilya, Avustralya, Hawaii, Hindistan, Peru, Portekiz, Kolombiya, İran, Filipinler gibi birçok ülkede dağılım göstermektedir (Demite ve ark., 2014). Türkiye'de ise Akyazı ve ark., (2016) tarafindan Ordu ilinde Trabzon hurmasında tespit edilmiştir.

$\mathrm{Bu}$ çalışma ile $A$. herbicolus erik ve kızılcık üzerinde Calvolia sp., T. californicus ve B. paraobliqua türleri ile birlikte bulunmuştur.

İncelenen materyal: Merkez, 29.06.2016, $P$. domestica (1 ㅇ), Gülyalı, 02.08.2016, C. mas (2 우우).

\subsubsection{Aristadromips masseei (Nesbitt)}

Yayılışı ve habitatı: Dünyada Kanada, İsviçre, İspanya, Rusya ve Almanya gibi birçok ülkede bulunmuştur (Demite ve ark., 2014). Türkiye'de daha önce Giresun (Çobanoğlu, 1991-1992) ve Ordu'da farklı bitkilerden toplanmıştır (Soysal ve Akyazı, 2018).

$\mathrm{Bu}$ çalışmada ise Ordu'da erik yapraklarında $P$. ulmi ile birlikte elde edilmiştir.

İncelenen materyal: Kumru, 28.07.2016, $P$. domestica (1 +).

\subsubsection{Euseius finlandicus (Oudemans)}

Yayılışı ve habitatı: Euseius finlandicus, İtalya, Fransa, Japonya ve Amerika gibi pekçok ülkede tespit edilmiştir (Demite ve ark., 2014). Türkiye'de ise Erdoğan, (2013), türü, Tokat'ta erik, kiraz, şeftali, vişne, kayıs1 ve mahlep yapraklarından yoğun olarak elde etmiştir. Güven (2008) ise, İzmir şeftali bahçelerinde $E$. finlandicus'un varlığından söz etmiştir. Tür, sert çekirdekli meyvelerin dışında farklı habitatalarda da bulunmuştur (Önuçar ve Ulu, 1988; Çobanoğlu, 1993a; Yanar ve Ecevit, 2005; Kasap ve Çobanoğlu, 2007, 2009; Özman ve Çobanoğlu, 2001; Akyazı ve Ecevit, 2003; Kasap ve ark., 2008; Denizhan ve Çobanoğlu, 2009; Özsisli ve Çobanoğlu, 2011; Göven ve ark., 2009; Kasap, 2014; Çobanoğlu ve Kumral, 2014, 2016; Kutlu, 2016; Kumral ve Çobanoğlu, 2016; Yeşilayer ve Uçar, 2016; Çobanoğlu ve Güldalı, 2017; İnak ve Çobanoğlu, 2018).

Ordu ilinde de erik, kiraz, şeftali ve kızılcık yapraklarından Calvolia sp., T. californicus, C. pulcher, T.goetzi, D. gigantorhynchus, B. rubrioculus, A. viennensis, B. paraobliqua ve $R$. dudicihi türleri ile birlikte toplanmıştır.

İncelenen materyal: Akkuş, 05.08.2016, P. domestica $(13)$, P. avium (1 + ), Gülyal1, 02.08.2016, P. avium (3 우), C. mas (5 우), Kabadüz, 09.08.2016, P. domestica (2 우), 21.07.2017, P. avium (1 ㅇ),Merkez, 29.06.2016, P. domestica (1 + ), Perşembe, 21.06.2016, P. avium (1 P), P. persica (2 O 9 ), Ulubey, 20.09.2016, P. domestica (1 ㅇ), P. avium (1 ㅇ), C. mas (4 우), 29.06.2017, P. domestica (3 + + ), Ünye, 22.06.2016, P. domestica (10 웅), P. avium (4 웅), 21.07.2017, P. domestica (1 đ̂), P. $\operatorname{avium}(4 \circ$ 우, $1 \mathrm{nimf})$.

\subsubsection{Galendromus longipilus Nesbitt}

Yayılışı ve habitatı: Dünyada Meksika, Macaristan, Amerika Birleşik Devletleri, Kanada, İtalya, Almanya, 
Polonya ve İspanya gibi birçok ülkede tespit edilmiştir (Demite ve ark., 2014). Türkiye'de Adapazarı (Çobanoğlu, 1991-1992), Samsun, Ordu, Giresun ve Trabzon'da (Özman ve Çobanoğlu, 2001) farklı bitkilerde belirlenmiştir.

Tür bu çalışmada, erik ve kiraz da T. urticae, $B$. rubrioculus, A. viennensis, B. paraobliqua ve Calvolia sp. ile birlikte elde edilmiştir.

İncelenen materyal: Kabadüz, 09.08.2016, $P$. domestica (1 +, 1 đ), Merkez, 29.06.2016, P. domestica (3 우), Ulubey, 20.09.2016, P. avium (1 ㅇ), Ünye, 21.07.2017, P. domestica (1 ㅇ).

\subsubsection{Neoseiulella tiliarum (Oudemans)}

Yayılış1 ve habitatı: Dünya da yayılış gösterdiği ülkeler arasında İtalya, Makedonya, İspanya, Ukrayna, Almanya ve Kanada yer almaktadır (Demite ve ark., 2014). Türkiye'de Edirne ve Tekirdağ' da erikte (Çobanoğlu, 2004) bulunmuştur. Bunun dışında farklı illerde ve habitatalarda da kayıtlanmıştır (Özman ve Çobanoğlu, 2001; Akyazı ve Ecevit, 2003; İnal, 2005; Özsayın, 2012).

Bu çalışmada da erik, kiraz, şeftali ve kızılcıkta, $C$. pulcher, Calvolia sp., B. rubrioculus, T. triophthalmus ve B. paraobliqua türleri ile birlikte elde edilmiştir.

İncelenen materyal: Akkuş, 05.08.2016, $P$. domestica (2 우, 1 đ), C. mas (1 ㅇ) , Çaybaş1, 11.08.2016, P. domestica (1 ㅇ), Kumru, 28.07.2016, P. domestica (1 ㅇ), $P$. avium (1 9 ), $P$. persica (5 우), Ünye, 22.06.2016, $P$. domestica (1 + $)$, P. persica $(1$ \% , 1 đ).

\subsubsection{Paraseiulus soleiger (Ribaga)}

Yayılışı ve habitatı: Dünya da Rusya, İtalya ve Kanada başta olmak üzere 40'a yakın ülkede yayılış göstermektedir (Demite ve ark., 2014). Türkiye'de Tokat'ta sert çekirdekli meyvelerden erik, vişne ve mahlep ağaçlarında (Erdoğan, 2013) dağılımı bildirilmiştir. Tür, Türkiye'de diğer bazı bitkilerde de belirlenmiştir (Swirski ve Amitai, 1982; Çobanoğlu, 1993c; Akyazı ve Ecevit, 2003; Çobanoğlu, 2004; İnal, 2005; Yanar ve Ecevit, 2005; Yarpuzlu ve ark., 2008; Göven ve ark., 2009; Faraji ve ark., 2011; Özsayın, 2012; Kasap ve ark., 2013; Gençer Gökçe, 2015; Nas ve Güler, 2015; Yeşilayer ve Uçar, 2016).

Ordu ilinde ise kiraz ve kızılcık yapraklarından, Calvolia sp. ve $T$. californicus türleri ile birlikte toplanmıştır.

İncelenen materyal: Akkuş, 05.08.2016, P. avium (1 우), C. $\operatorname{mas}(3$ 웅).

\subsubsection{Paraseiulus triporus (Chant and Yoshida-Shaul)}

Yayılışı ve habitatı: Dünyada Çek Cumhuriyeti, Almanya, Moldova, Amerika Birleşik Devletleri, Kazakistan, Polonya ve Ukrayna gibi birçok ülkede kayıtlandığı bilinmektedir (Demite ve ark., 2014). Türkiye'de daha önce kızılcıkta Çobanoğlu, (2004) tarafından kayıtlanmıştır. Daha sonra, Tokat'ta erik, vişne ve kiraz (Erdoğan, 2013) yapraklarından toplanmıştır. Sert çekirdekli meyvelerin haricinde farklı habitatlarda tespiti vardır (Kasap ve Çobanoğlu, 2007; Yeşilayer ve Çobanoğlu, 2011; Özsisli ve Çobanoğlu, 2011; Özsayın 2012; Kasap ve ark., 2013; Satar ve ark., 2013; Gençer Gökçe, 2015; Akyazı ve ark., 2017; İnak ve Çobanoğlu, 2018).

$\mathrm{Bu}$ çalışmada erik ve kiraz ağaçlarında $D$. gigantorhynchus, C. pulcher, B. rubrioculus, Calvolia sp. ve $T$. goetzi ile birlikte toplanmıştır.

İncelenen materyal: Merkez, 29.06.2016, $P$. domestica (1 †), Gülyalı, 02.08.2016, P. avium (1 ㅇ).

\subsubsection{Phytoseius finitimus Ribaga}

Yayılışı ve habitatı: Dünyada İtalya başta olmak üzere İsrail, Fas, Portekiz, Tunus, Yunanistan ve Misır gibi 15 farklı ülkede tespit edilmiştir (Demite ve ark., 2014). P. finitimus, Türkiye'de sert çekirdekli meyvelerden, erik ağaçlarında (Erdoğan, 2013) tespit edilmiştir. Tür, diğer bazı illerde farklı bitkilerden de elde edilmiştir (Swirski ve Amitai, 1982; Düzgüneş ve Kılıç 1983; Çobanoğlu, 1993d; İncekulak ve Ecevit, 2002; Çobanoğlu 1989; Akyazı ve Ecevit, 2003; İnal, 2005; Özsisli ve Çobanoğlu, 2011; Yeşilayer ve Çobanoğlu, 2011; Kasap ve ark., 2013; Çobanoğlu ve Kumral, 2014, 2016; Kasap, 2014; Gençer Gökçe, 2015; Kumral ve Çobanoğlu, 2015b; Yeşilayer ve Uçar, 2016; Kutlu, 2016; Akyazı ve ark., 2017; Çobanoğlu ve Güldalı, 2017; Soysal ve Akyazı, 2018; İnak ve Çobanoğlu, 2018).

Bu çalışma ile Ordu'da, T. urticae, B. rubrioculus, $P$. ulmi, A. viennensis, $R$. dudichi, Calvolia sp., $D$. gigantorhynchus, $C$. pulcher, $T$. triophthalmus, Homeopronematus sp., Pronematus sp., T. californicus, $T$. goetzi ve B. paraobliqua türleri ile birlikte, erik, kiraz ve şeftali ağaçlarından toplanmıştır.

İncelenen materyal: Fatsa, 14.06.2016, P. domestica $(13), 29.06 .2017$, P. domestica (1 ㅇ), P. avium (2 우), Gülyal1, 02.08.2016, P. domestica $(12$ 우, 1 ○),P. avium (5 우), İkizce, 11.08.2016, $P$. domestica (3 우), Kabadüz, 09.08.2016, P. domestica (4 우, 1 §), $P$. avium (2 đo ô, 1 nimf), Merkez, 29.06.2016, P. domestica

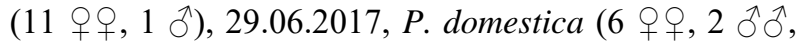
1nimf), $P$. avium (2 o+ ), Perşembe, 21.06.2016, $P$. domestica (4 우), P. persica (2 우), 21.07.2017, P. domestica $(1$ +, 1 ( ), Ulubey, 20.09.2016, P. domestica

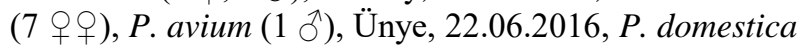
(16 웅, 1 nimf), $P$. avium (1 ㅇ), 21.07.2017, $P$. domestica $(3$ 우, 1 đ $)$.

\subsubsection{Phytoseiulus persimilis Athias-Henriot, 1957}

Yayılışı ve habitatı: Dünyada İtalya, İspanya, Suriye, Tunus, Amerika Birleşik Devletleri, İsrail, Çin, Kıbrıs, Fransa ve Avustralya gibi birçok ülkede yayılım göstermektedir (Demite ve ark., 2014). Türkiye'de sert çekirdeklilerin dışında, Alanya, Mersin ve Antakya'da (Şekeroglu ve Kazak, 1993). Samsun'da (İnal, 2005; 
Akyazı ve Ecevit, 2008), Çanakkale'de (Kasap ve ark., 2013), Ankara ve Bursa'da (Çobanoğlu ve Kumral, 2014), Adana'da (Nas ve Güler, 2015), Ordu'da (Soysal ve Akyazı, 2018) ve Mersin'de (Çobanoğlu ve Güldalı, 2017) farklı konukçularda tespit edilmiştir.

Ordu'da ise erik yapraklarından, T. urticae, A. viennensis ve $T$. californicus türleri ile bilikte toplanmıştır.

İncelenen materyal: Perşembe, 21.06.2016, $P$. domestica (1 + ).

\subsubsection{Phytoseius ribagai Athias-Henriot}

Yayılışı ve habitatı: Dünya'da Cezayir, Avusturya, İtalya, Norveç, Sırbistan ve İspanya'da kayıtlanmıştır (Demite ve ark., 2014). Türkiye'de Kırklareli'nde findık ağaçlarında (Çobanoğlu, 2004) tespit edilmiştir.

Bu çalışma ile kızılcık yapraklarından, E. uncatus ile birlikte elde edilmiştir.

İncelenen materyal: Akkuş, 05.08.2016, C. mas (1 ㅇ).

\subsubsection{Transeius wainsteini (Gomelauri)}

Yayılışı ve habitatı: Dünya'da Danimarka, Gürcistan, Almanya, İran ve Slovakya'da dağılım göstermektedir (Demite ve ark., 2014). Türkiye'de ise Giresun'da kuşburnu (Faraji ve ark., 2011) ve Ordu'da Trabzon hurmasında (Akyazı ve ark., 2016; Soysal ve Akyazı, 2018) tespit edilmiştir.

$\mathrm{Bu}$ çalışmada ise erik, kiraz, şeftali ve vişne yapraklarında, B. rubrioculus, T. urticae, A. viennensis, D. gigantorhynchus, $R$. dudicihi, T. californicus, $T$. goetzi, B. paraobliqua, $T$. triophthalmus, Homeopronematus sp. ve Calvolia sp. türleri ile birlikte bol miktarda bulunmuştur.

İncelenen materyal: Çaybaşı, $P$. domestica $(1$ đ), $P$. avium (3 ठㅈ), Fatsa, 14.06.2016, P. domestica (5 + , 2

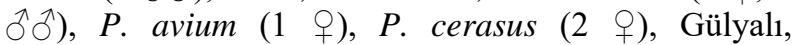
02.08.2016, $P$. domestica (1 + ), $P$. avium (3 + ), İkizce, 11.08.2016, P. domestica (2 우, 1 §), P. avium (3 ㅇ) ), Kumru, 28.07.2016, P. domestica (3,+ 1 §), P. avium (7

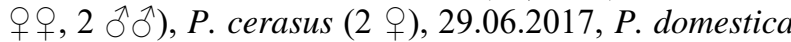
$(1$ †, 1 §), $P$. avium (1 + ), Kabadüz, 09.08.2016, $P$. domestica (3 우), P. avium (1 우 1 đ), Merkez, 29.06.2016, $P$. domestica (2 우), 29.06.2017, $P$. domestica (1 ㅇ), Perşembe, 21.07.2017, P. avium (1 ㅇ), Ulubey, 20.09.2016, P. domestica (18 우), P. avium (3 웅), 29.06.2017, P. domestica (1 ㅇ), Ünye, 22.06.2016, P. domestica (3 웅, 1 §), P. avium (5 우우), P. persica (1 ㅇ, 1 nimf), 21.07.2017, P. domestica (6 웅, 1 ठ).

\subsubsection{Typhlodromus (Anthoseius) bakeri (Garman)}

Yayıl1şı ve habitatı: Dünya'da Kanada başta olmak üzere Çek Cumhuriyeti, Finlandiya, Fransa, Almanya, Hollanda, Azerbaycan, Norveç, Polonya, Danimarka ve İran gibi birçok ülkede tespit edilmiştir (Demite ve ark., 2014). Türkiye'de Kastamonu (Çobanoğlu, 1993d) ve
Edirne'de (Çobanoğlu, 2004) sert çekirdeklilerin dışında farklı habitatlardan örneklenmiştir.

Ordu'da ise erik, kiraz ve şeftali ağaçlarında, $C$. pulcher, B. rubrioculus, T. californicus, Calvolia sp., $T$. triophthalmus ve Homeopronematus sp. türleri ile birlikte tespit edilmiştir.

İncelenen materyal: Akkuş, 05.08.2016, P. domestica (2 우), P. avium (11우), Çaybaş1, 11.08.2016, $P$. domestica (1 †), Gülyalı, 02.08.2016, P. persica (1 $\odot)$, Kabadüz, 09.08.2016, P. domestica (3 우), P. avium (1 )),Perşembe, 21.06.2016, P. avium (1 + ).

\subsubsection{Typhlodromus (Anthoseius) rhenanus (Oudemans)}

Yayılışı ve habitatı: Dünya'da Beyaz Rusya, Brezilya, İran, İsrail, Hollanda, Portekiz, Rusya, Norveç ve Slovakya gibi 40 ülkede kayıtlanmıştır (Demite ve ark., 2014). Türkiye'de Antalya (Çobanoğlu, 1989a), Ordu, Giresun ve Trabzon'da (Özman ve Çobanoğlu, 2001) sert çekirdekli meyvelerin dışında farklı bitkilerde tespit edilmiştir.

Bu çalışmada ise Ordu ilinde erik ve kızılcıkta $T$. triophthalmus ile birlikte elde edilmiştir.

İncelenen materyal: Akkuş, 05.08.2016, P. domestica (1 ㅇ, 1 đ), C. mas (1,+ 1 đ), Kumru, 28.07.2016, P. domestica $(1$ + $)$.

\subsubsection{Typhlodromus (Typhlodromus) tiliae (Oudemans)}

Yayılışı ve habitatı: Dünyada Almanya, İtalya, Macaristan, Ukrayna, Kıbrıs, Fransa, Rusya, İsveç ve Mısır gibi 40 tan fazla ülkede yayıllş̧ göstermektedir (Demite ve ark., 2014). Türkiye'de farklı araştırmacılarca (Swirski ve Amitai 1982; Çobanoğlu 1989; Göven ve ark., 2009; Yeşilayer ve Çobanoğlu 2011; Kumral ve Çobanoğlu, 2015b), sert çekirdeklilerin dışında farklı bitkiler üzerinde tespit edilmiştir.

Ancak, bu çalışma ile erik yapraklarından $T$. triophthalmus ile birlikte toplanmıştır.

İncelenen materyal: Çaybaşı, 11.08.2016, $P$. domestica (1 P).

\section{Sonuç ve Öneriler}

$\mathrm{Bu}$ çalışma, Ordu ilinde sert çekirdekli meyvelerde bulunan akar faunasinın belirlenmesi amaciyla, 20162017 yılları arasında iki vejetasyon dönemi boyunca yürütülmüştür. Örneklemeler Ordu ilinin toplam 11 ilçesinde gerçekleştirilmiştir. Sörveyler boyunca, 5 farklı sert çekirdekli meyve türünden 474 örnekleme yapılmıştır. Çalışmada en çok örneklenen sert çekirdekli meyve türü, toplam 267 örnekleme ile erik olmuştur. Bunu sırasıyla kiraz (116), şeftali (46), vişne (29) ve kızılcık (16) örneklemeleri takip etmiştir.

Çalışma boyunca, elde edilen toplam akar sayısı 1265'dir (Çizelge 3). Örneklemelerde tespit edilen akarlar, familya bazında incelendiğinde, en yoğun 
bulunan familyalar, Tetranychidae $\left(\begin{array}{ll}\% & 28\end{array}\right)$ ve Phytoseiidae (\% 25) olmuş, bunu sırasıyla Tydeidae (\% 21), Winterschmidtiidae (\% 11), Triophtydeidae (\% 6),
Diptilomiopidae (\% 4), Tenuipalpidae (\% 2), Iolinidae $\left(\begin{array}{l}\% \\ \%\end{array}\right)$, Eriophyidae (\% 1), Cunaxidae $\left(\begin{array}{ll}\% & 0.1\end{array}\right)$ ve Stigmaeidae (\% 0.1) familyaları takip etmiştir (Şekil 2).

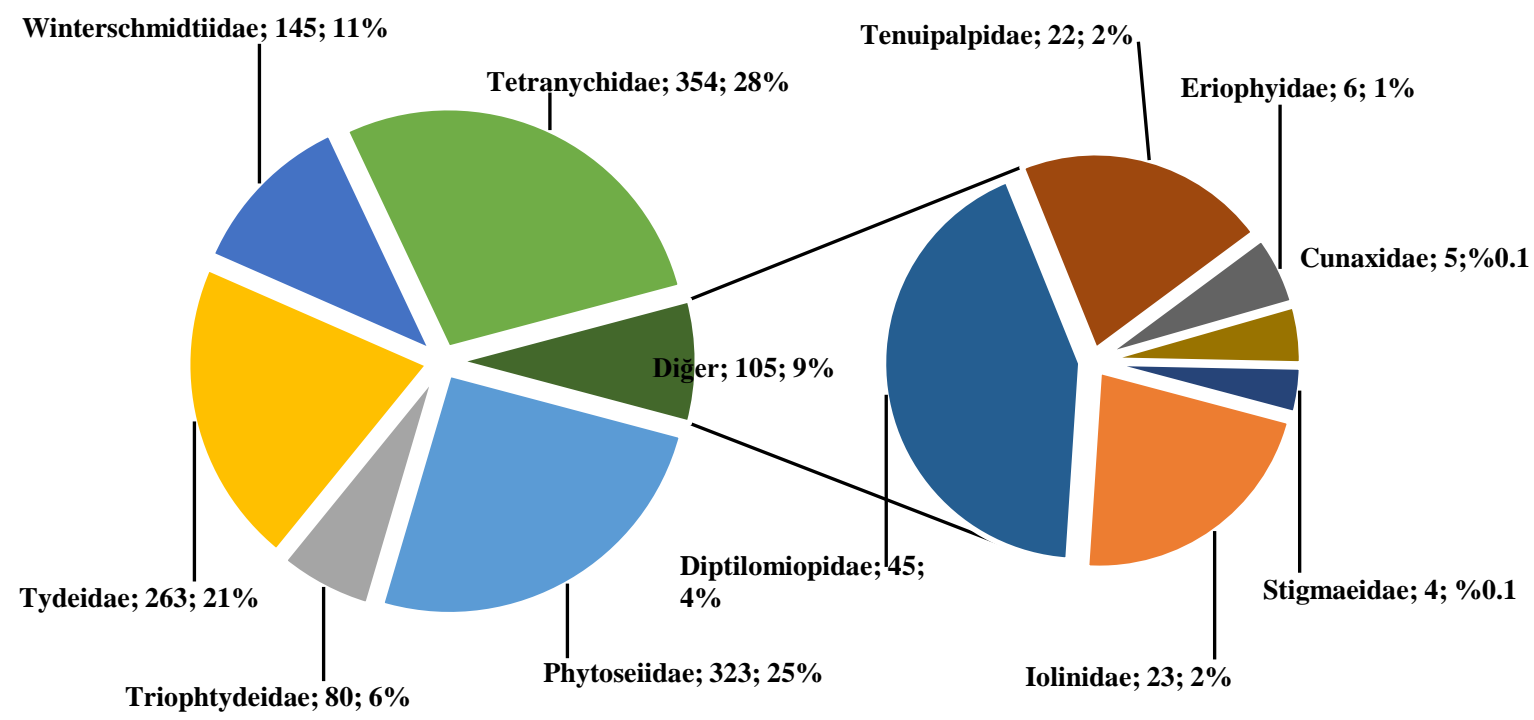

Şekil 2. Tespit edilen akarların familyalara göre dağılımı

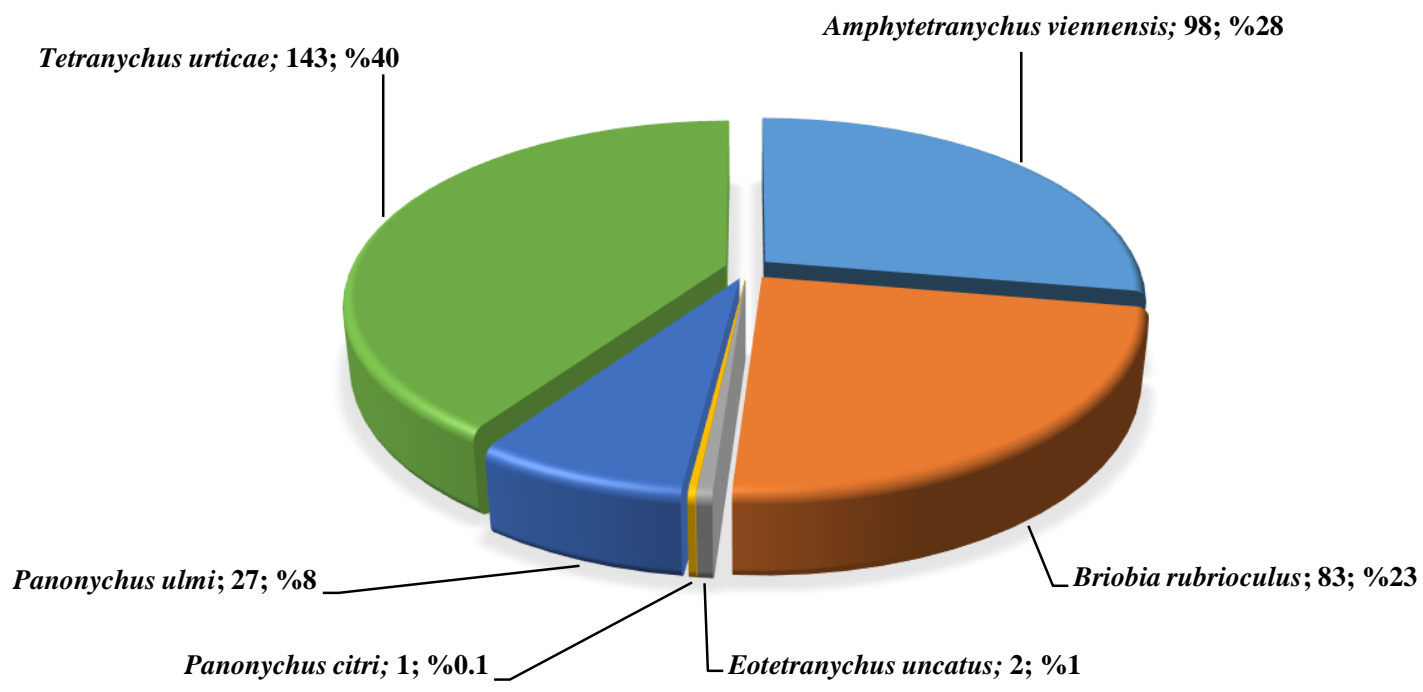

Şekil 3. Tetranychidae familyasından tespit edilen akarların tür bazında dağılımı

Tetranychidae familyasından 6 tür tespit edilmiş olup, en baskın tür, T. urticae (\% 40)' dir. Onu sırası ile A. viennensis (\% 28), B. rubrioculus (\% 23), P. ulmi (\% 8), E. uncatus $(\%$ 1) ve P. citri (\% 0.1$)$ türleri takip etmiştir (Şekil 3).

Phytoseiidae familyasından 15 tür teşhis edilmiştir. Phytoseiid akarlar içerisinde en yaygın tür $T$. wainsteini (\% 30) olmuştur. Bu türü $P$. finitimus (\% 29), E. finlandicus (\% 15), A. andersoni (\% 7) T. bakeri (\% 6), N. tiliarum (\% 5), G. longipilus (\% 2), T. rhenanus (\% 2),
A. herbicolus (\% 1), P. soleiger (\% 1), P. triporus (\% 1), A. masseei (\% 1), P. persimilis (\% 0.1), P. ribagai (\% 0.1 ) ve T. tiliae (\% 0.1) türleri takip etmiştir (Şekil 4). Ayrıca, Teuipalpidae familyasından 2 tür, Diptilomiopidae familyasından 2 tür, Eriophyidae familyasından 1 tür, Tydeidae familyasından 3 tür, Stigmaeidae familyasından 2 tür, Iolinidae familyasından 2 tür, Triophtydeidae familyasından 1 tür, Cunaxidae familyasından 1 tür ve Winterschmidtiidae familyasından 1 tür belirlenmiştir. 


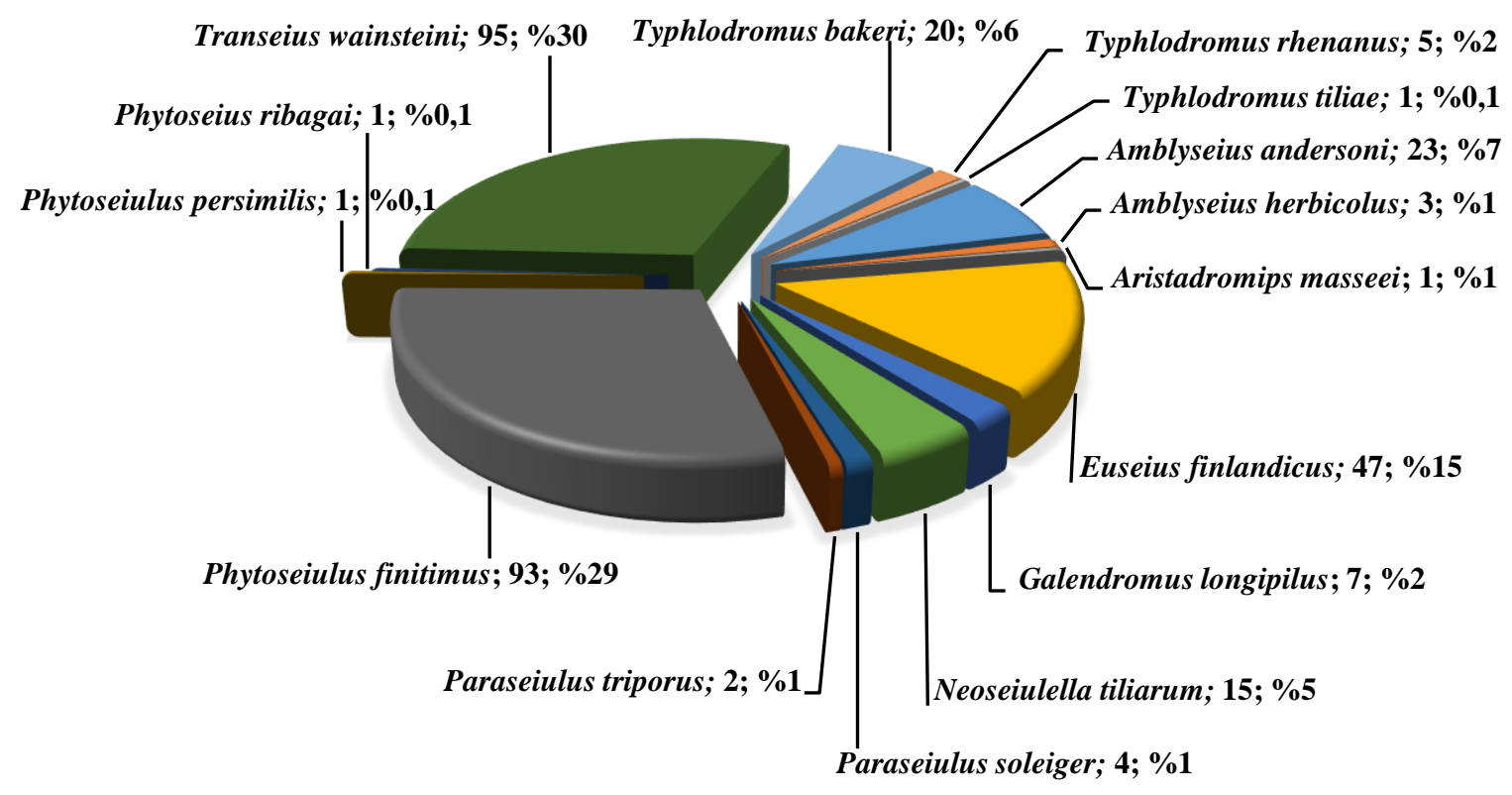

Şekil 4. Phytoseiidae familyasından tespit edilen akarların tür bazında dağılımı

Özetle, Ordu ilinde sert çekirdekli meyvelerde yapılan örneklemeler sonucunda toplam 36 farklı tür tespit edilmiştir. Belirlenen tür sayısının fazla oluşu bölgedeki meyve ağaçlarının doğal faunasının bozulmadığını gösterir niteliktedir. Ordu ilinde sert çekirdekli meyveler genellikle, ev bahçelerinde, findık bahçesi içlerinde, ormanlarda, yol kenarlarında ve hobi bahçelerinde kimyasal kullanılmadan yetiştirilmektedir. $\mathrm{Bu}$ sayede, doğal dengenin korunduğu ve bununda tür çeşitliliğini olumlu yönde etkilediği düşünülmektedir.

Biyopreparatı olan predatör türlerden $P$. persimilis ve A. andersoni'nin (Anonim, 2018b) Ordu'nun doğal ekosisteminden elde edilmiş olması ise, yöre için önemli ve iyi bir durumu ortaya koymaktadır. Ayrıca tespit edilen diğer phytoseiid türlerin de, mücadele potansiyellerinin olduğu düşünülmektedir. $\mathrm{Bu}$ nedenle ileriki çalışmalarda, bu türlerin yörede baskın zararlı türler olarak belirlenen $T$. urticae, A. viennensisve $B$. rubrioculus'un biyolojik mücadelelerindeki etkinliklerinin Ordu ili koşullarında araştırılması gerekmektedir.

\section{Teşekkür}

$\mathrm{Bu}$ çalışma Ordu Üniversitesi Bilimsel Araştırma Projeleri Koordinatörlüğünün TF-1622 numaralı projesi ile desteklenmiştir. Tespit edilen türlerin, teşhis onaylamalarını yapan Prof. Dr. Sultan Çobanoğlu, Prof. Dr. Eddie A. Uckermann, Prof. Dr. Noeli J. Ferla, Dr. Philippe Auger, Dr. Pavel B. Klimov'a ve laboratuvarını ziyaret esnasında, taksonomik bilgi ve literatürlerini paylaşan Sayın Dr. Mariusz Lewandowski (Warsaw Univesity of Life Sciences/Poland)'ye teşekkür ederiz. Ayrıca, çalışmayı değerlendirmek için harcadıkları zaman ve eserin geliştirilmesi yönünde yapmış oldukları değerli tavsiyelerinden dolayı sayın hakemlere teşekkürü borç biliriz.

\section{Kaynaklar}

Akbolat, D., Alğın, B., Ekinci, K., Yılmaz, Ş., 2006. Isparta İlindeki Elma Bahçelerinde Mekanik Yabancı Ot Savaş Yönteminin Kullanılma Durumunun Belirlenmesi. Süleyman Demirel Üniversitesi Fen Bilimleri Enstitüsü Dergisi 10(1), 33-39.

Akyazı, F., Ecevit, O., 2003. Determination of Mite Species in Hazelnut Orchards in Samsun, Ordu and Giresun Provinces. Ondokuz Mayıs Üniversitesi Ziraat Fakültesi Dergisi 18, 39-45.

Akyazı, F., Ecevit, O., 2005. Samsun İli Fındık Bahçelerinde Bulunan Zararlı ve Yararlı Akarların Populasyon Dalgalanmalarının Belirlenmesi. Gazi Osman Paşa Üniversitesi Ziraat Fakültesi Dergisi 22, 13-18.

Akyazı, R., Ecevit, O., 2008. Samsun İli Hıyar Seralarında Predatör Akar Phytoseiulus persimilis Athias-Henriot (Acarina: Phytoseiidae)'in Dağılımı. MKU Ziraat Fakültesi Dergisi 13, 73-85.

Akyazı, R., Ueckermann E.A., Soysal M., 2016. The new distribution of Amblyseius herbicolus in Turkey (Parasitiformes, Phytoseiidae) with a key of Amblyseius species found in Turkey. Acarologia 56, 237-244.

Akyazı, R., Ueckermann E.A., Akyol D., Soysal M., 2017. Distribution of mite species (Acari) on persimmon trees in 
Turkey (Ordu), with one newly recorded mite species and one re-described species. International Journal of Acarology 43, 563-581.

Alaoğlu, Ö., 1984. Erzurum ve Erzincan Yörelerindeki Bazı Bitkilerde Bulunan Eriophyoidea (Acarina: Actinedida) Akarlarının Sistematiği ve Zarar Şekli Üzerinde Çalışmalar. Doktora Tezi, Atatürk üniversitesi, Fen Bilimleri Enstitüsü, Bitki Koruma Ana Bilim Dalı, Erzurum.

Alaoğlu, Ö., 1991. Two New Records Of Eriophyid Mites (Acarina: Eriophyoidea) For The Turkish Fauna. Atatürk Üniversitesi Ziraat Fakültesi Dergisi, 22,72-77.

Amrine, J.W., Manson, D., 1996. Preparation, mounting and descriptive study of Eriophyoid mites. Ed.: Lindquist, E.E., Sabelis, M.W., inside: Eriophyoid Mites-Their Biology, Natural Enemies And Control. Elsevier, Amsterdam, 383 396.

Amrine, J.W., Stasny, T.A., Fletchmnn, C.H.W., 2003. Revised keys to world genera of Eriophyoidae. Indıra Publishing House, 244pp.

Anonim, 2012. Sert Çekirdekli Meyve Yetiştiriciliği-2. Içinde: Tarim Teknolojileri. T.C. Millî Eğitim Bakanliği, Ankara, s 101.

Anonim, 2018a. Yaş meyve ve sebze sektörü türkiye geneli değerlendirme raporu 2016/2017 Ocak-Aralık Dönemi. Akdeniz İhracatçı Birlikleri Genel Sekreterliği, Mersin.

Anonim, 2018b. Biobest. Faydalı böcekler ve akarlar https://www.biobestgroup.com/tr/biobest/\%C3\%BCr\%C3 $\%$ BCnler/biyolojik-mucadele-

15872/\#productGroup_15084 (Erişim tarihi: 20 Nisan 2018).

Auger, P., Migeon, A., Ueckermann, E.A., Tiedt, L., Navajas, M., 2013. Evidence for synonymy between Tetranychus urticae and Tetranychus ciinabarinus (Acari Prostimata, Tetranychiae): Review and new data. Acarologia, 53(4), 383-415.

Baldo, F.B., Raga, A., de Carvalho Mineiro, J.L., de Castro, J.L., 2016. Diversity and dynamics of populations of mites in nectarine trees (Prunus persica var. nucipersica) (Rosaceae). Journal of Plant Studies, 5(1), 28.

Bayram, Ş., Çobanoğlu, S., 2007. Mite fauna (Acari: Prostigmata , Mesostigmata, Astigmata) of coniferous plants in Turkey. Türkiye Entomoloji Dergisi, 31(4), 279 290.

Boczek, J., 1964. Studies on Eriophyid Mites of Poland III. Annales Zoologici, 11:221-236.

Bohinc. T., Trdan, S., 2012. Phytophagous and predatory mites in slovenia. Acarologia, 53(2), 145-150.

Bulut, H.S., Madanlar, N., 2005. Bademli (Ödemiş, İzmir ) Beldesi Meyve Fidanlıklarında Topraküstünde Saptanan Zararlı Böcek ve Akar Türleri İle Doğal Düşmanları. Ege Üniversitesi Ziraat Fakültesi Dergisi, 42(1), 67-74.

Çetin. G., Hantaş, C., Erenoğlu, B., 2006. Bursa ve Yalova'da Bögürtlen (Rubus fruticocus) Bahçelerinde Saptanan Zararlı Böcek, Akar Faunası Üzerinde Çalışmalar. Bahçe, 35, 61-74.

Çobanoğlu, S., 1989a. Antalya İli Sebze Alanlarında Tespit Edilen Phytoseiidae Berlese, 1915 (Acarina: Mesostigmata) Türleri. Bitki Koruma Bülteni, 29 (1-2), 47 64.

Çobanoğlu, S., 1989b. Türkiye'nin bazı Turunçgil bölgelerinde tespit edilen faydalı akar (Acari, Phytoseiidae) türleri. Türkiye Entomoloji Dergisi, 13(3), 163-178.

Çobanoğlu, S., 1989c. Türkiye için üç yeni faydalı akar (Acari: Phytoseiidae) türü. Türkiye Entomoloji Dergisi, 13(4): 229-38.
Çobanoğlu, S., 1991-1992. An annotated list of hazel of Turkey. Israel Journal of Entomology, 25, 35-40.

Çobanoğlu, S., 1993a. Türkiye' nin önemli elma bölgelerinde bulunan Phytoseiidae (Parazitiformes) türleri üzerinde sistematik çalışmalar I. Türkiye Entomoloji Dergisi, 17(1), 41-45.

Çobanoğlu, S., 1993b. Türkiye'nin önemli elma bahçelerinde bulunan Phytoseiidae (Parasitiformes) türleri üzerinde sistematik çalışmalar II. Türkiye Entomoloji Dergisi, 17(2), 99-116.

Çobanoğlu, S., 1993c. Türkiye' nin önemli elma bölgelerinde bulunan Phytoseiidae (Parazitiformes) türleri üzerinde sistematik çalışmalar III. Türkiye Entomoloji Dergisi, 17(3), 145-192.

Çobanoğlu, S., 1993d. Türkiye' nin önemli elma bölgelerinde bulunan Phytoseiidae (Parazitiformes) türleri üzerinde sistematik çalışmalar IV. Türkiye Entomoloji Dergisi 17(4), 239-255.

Çobanoğlu, S., 2004. Phytoseiid mites ( Mesostigmata: Phytoseiidae ) of Thrace , Turkey. Israel Journal of Entomology, 34, 83-107.

Çobanoğlu, S., 2008. Mites (Acari) associated with stored apricots in Malatya, Elazığ and İzmir provinces of Turkey. Türkiye Entomoloji Dergisi, 32(1), 3-20.

Çobanoğlu, S., Düzgüneş, Z., 1986. Ankara İlinde Önemli Meyve Ağaçlarında Tespit Edilen Kabuklubitler. Bitki Koruma Bülteni, 26(3-4), 135-158.

Çobanoğlu, S., Güldalı, B., 2017. Plant Parasitic and Predatory Mites ( Acari: Tetranychidae, Phytoseiidae ) and Population Density Fluctuation of Two-Spotted Spider Mite ( Tetranychus urticae Koch ) on Strawberry in the Mersin Province of Turkey. Research \& Reviews: Journal of Zoological Sciences, 5(2), 57-67.

Çobanoğlu, S., Kazmierski, A., 1999. Tydeidae and Stigmaeidae [Acari: Prostigmata] from orchards, trees and shrubs in Turkey. Biological Bulletin of Poznan, 36(1), 7183.

Çobanoğlu, S, Kumral, N.A., 2014. Ankara, Bursa ve Yalova illerinde domates yetiştirilen alanlarda zararli ve faydali akar (Acari) biyolojik çeşitliliłi ve popülasyon dalgalanmasi. Turkiye Entomoloji Dergisi 38(2), 197-214.

Çobanoğlu, S, Kumral, N.A., 2016. The biodiversity, density and population trend of mites (Acari) on Capsicum annuum L. in temperate and semi-arid zones of Turkey. Systematic and Applied Acarology, 21(2), 907-918.

Çobanoğlu, S., Ueckermann, E., Sağlam, H.D., 2016. The Tenuipalpidae of Turkey, with a key to species (Acari: Trombidiformes). Zootaxa, 4097(2), 151-186.

De Lillo, E., 1997. New Eriophyoid mites (Acari: Eriophyoidea) from Italy III. Entomologica Bari 31:133142.

Deligöz. İ., Değirmenci, K., Sökmen, M., 2015. Determination of Plum pox virus, the causal agent of Sharka Disease, in Samsun Province. Anadolu Journal of Agricultural Sciences, 30(3), 227.

Demite. P.R., Mcmurtry, J.A., De Moraes, G.J., 2014. Phytoseiidae database: A website for taxonomic and distributional information on phytoseiid mites (Acari). Zootaxa, 3795:571-577.

Denizhan, E., 2007. Ankara ilinde park ve süs bitkilerinde Eriophyoidea (Acarina) türleri, konukçulari, yayginliklari ve doğal düşmanlarinin saptanmasi ile zararlı Aculus schlechtendali (Nalepa,1892)' nin popülasyon gelişimi üzerine araştirmalar. Doktora Tezi, Ankara Üniversitesi Fen Bilimleri Enstitüsü, 267s, Ankara. 
Denizhan, E., Çobanoğlu, S., 2010. Eriophyoid mites (Acari: Prostigmata: Eriophyoidea) in Van Lake Basin from Turkey. International Journal of Acarology, 36(6), 503510.

Düzgüneş, Z., 1952. Türkiye' de turunçgil akarları. Bitki Koruma Bülteni, 1:6-11.

Düzgüneş, Z., 1963. Türkiye' de yeni bulunan akarlar. Bitki Koruma Bülteni, 3:4, 237-246.

Düzgüneş Z., 1965. Türkiye'de bitkilerde zarar veren Tenuipalpidae Sayed familyası türleri üzerine incelemeler. Ankara Üniversitesi Ziraat Fakültesi Yıllığı. 3,120-148.

Düzgüneş, Z., Kılıç, S., 1983. Türkiye'nin önemli elma bölgelerinde bulunan Phytoseiidae (Acarina) türlerinin tespiti, bunlardan Tetranychus viennensisZacher (Acarina: Tetranychidae) ile ilişkileri bakımından en önemli türün etkinliği üzerine araştırmalar. Doğa, 7,193-205.

Ecevit, O.,1976. Akar (Acarina)'ların toplanması, saklanması ve preparatlarının yapılması. Atatürk Üniversitesi Yayınlar1, 480, 1-32.

Edward, W., Donald, M., 1987. The false spider mites of Mexico (Tenuipalpidae: Acari). Agricultural Research Service, Tectinical Bulletin, pp: 241.

Eichelberger, C.R., Johann, L., Majolo, F., Ferla, N.J., 2011. Mites fluctuation population on peach tree (Prunus persica (L.) Batsch) and in associated plants. Revista Brasileira De Fruticultura, 33(3), 765-773.

Elma, F.N., Alaoğlu, Ö., 2008. Konya ilinde peyzaj alanlarındaki ağaç ve çalılarda bulunan zararlı akar türleri ve doğal düşmanları. Türkiye Entomoloji Dergisi, 32(2), $115-129$.

Erdoğan, H., 2013. Tokat ilinde taş çekirdekli meyvelerde bulunan akar türlerinin belirlenmesi. Yüksek Lisans Tezi, Gaziosmanpaşa Üniversitesi Fen Bilimleri Enstitüsü, 97s, Tokat.

Erdoğan, H., Yanar, D., 2015. Tokat ilinde kayısı (Prunus armeniaca L.) ağaçlarında bulunan faydalı ve zararlı akar türlerinin belirlenmesi. Tarım Bilimleri Araştırma Dergisi, 8(1), 71-75.

Ertop, S., 2006. Çanakkale ili kiraz bahçelerindeki yararlı ve zararlı böcek ve akar türlerinin saptanması. Yüksek Lisans Tezi, Çanakkale Onsekiz Mart Üniversitesi Fen Bilimleri Enstitüsü, 66s, Çanakkale.

Ertop, S., Özpınar, A., 2011. Çanakkale İli kiraz ağaçlarındaki fitofag ve yararlı türler ile bazı önemli zararlıların popülasyon değişimi. Türkiye Entomoloji Bülteni, 1(2), 109-118.

Fan, Q.H., Zhang Z.Q., 2005. Raphignathoidea (Acari: Prostigmata), Fauna of New Zealand. 52, 400pp.

FAO, 2016. Food and agriculture data. http://www.fao.org/faostat/en/\#data/QC (Erişim tarihi: 20 Nisan 2018).

Faraji, F., Hajizadeh, J., Ueckermann, E.A., Kamali, K., McMurtry, J.A., 2007. Two new records for Iranian phytoseiid mites with synonymy and keys to the species of Typhloseiulus Chant \& MacMurtry and Phytoseiidae in Iran (Acari: Mesostigmata). International Journal of Acarology, 33(3), 231-239.

Faraji, F., Çobanoğlu, S., Çakmak, I., 2011. A checklist and a key for the Phytoseiidae species of Turkey with two new species records (Acari: Mesostigmata). International Journal of Acarology, 37(1), 221-243.

Geçer, E., Denizhan, E., 2015. Diyarbakır ili meyve ağaçlarında zararlı Eriophyoidea (Acarina) türlerinin saptanması. Bitki Koruma Bülteni 55(2), 95-105.

Gençer N.S., Coşkuncu K.S., Kumral N.A., 2005. Bursa İlinde İncir Bahçelerinde Görülen Zararlı ve Yararlı Türlerin
Saptanması Ondokuz Mayıs Üniversitesi Ziraat Fakültesi Dergisi 20(2):24-30.

Gençer Gökçe, P., 2015. Tekirdağ ili yeşil alanlarda süs bitkilerinde bulunan akar türlerinin saptanmasi. Yüksek Lisans Tezi, Namık Kemal Üniversitesi Fen Bilimleri Enstitüsü, 61s, Tekirdağ.

Gerson, U., Smiley, R.L., Ochoa, R., 2003. Mites (Acari) for pest control. Blackwell Science Publishing Ltd, Oxford, UK, pp558.

Gonzalez, R.H., 1965. A taxonomic study of the genera Mediolata, Zetzellia, and Agistemus (Acarina: Stigmaeidae). University of California Press. 64.

Göksu, M.E., 1968. Akdiken akari (Tetranychus viennensis Zacher)' nın biyolojisi, mücadelesi, yayılış sahası ve konukçuları üzerinde araştırmalar. Bitki Koruma Bülteni, 8(3), 194-213.

Göven, M.A., Çobanoğlu, S., Güven, B., 2009. Ege Bölgesi bağ alanlarındaki avcı akar faunası. Bitki Koruma Bülteni, 49(1), 1-10.

Gupta, S.K., Sanyal, A.K., 2004. Some new records of mites (Acari) from Bangladesh. Records of the Zoological Survey of India, 10:3-4, 17-24.

Güven, B., 2008. Izmir ili şeftali bahçelerinde zararlı akar türleri ile doğal düşmanları ve populasyon değişimlerinin saptanması üzerinde araştırmalar. Doktora Tezi, Ege Üniversitesi Fen Bilimleri Enstitüsü, 121s, İzmir.

Güven, B., Madanlar, N., 2011. İzmir ili şeftali bahçelerinde bulunan zararlı akarlar ile predatörü olan akar türleri. Türkiye Biyolojik Mücadele Dergisi, 2(2), 119-126.

Hazır, A., Ulusoy, M.R., 2012. Adana ve Mersin illeri şeftali ve nektarin alanlarında saptanan zararlılar ile predatör ve parazitoit türler. Türkiye Biyolojik Mücadele Dergisi, 3(2), 157-168.

Hessein N.A., Perring, T.M., 1986. Feeding habits of the Tydeidae with evidence of Homeopronematus anconai (Acari: Tydeidae) predation on Aculops lycopersici (Acari: Eriophyidae). International Journalof Acarology 12, 215221.

Heyer, J.D., Ueckermann, E.A., Khanjani, M., 2013. Iranian Cunaxidae (Acari: Prostigmata: Bdelloidea). Part III. Subfamily Cunaxoidinae. Journal of Natural History, 47(31-32), 2049-2070.

İnak, E., Çobanoğlu, S., 2018. Determination of mite species on vineyards of Ankara, Turkey. Fresenius Environmental Bulletin, 27(2), 1232-1239.

İnal, B., 2005. Bafra ve Çarşamba ovalarında çeşitli kültür bitkisi alanlarında bulunan acarina türleri üzerinde faunistik çalışmalar. Yüksek Lisans Tezi, Ondokuz Mayıs Üniversitesi Fen Bilimleri Enstitütüsü, 90s, Samsun.

İncekulak, R., Ecevit, O., 2002. Amasya ili elma bahçelerinde bulunan zararlı ve yararlı akar türleri ile popülasyon yoğunluklarının saptanması üzerinde bir araștırma. Türkiye 5. Biyolojik Mücadele Kongresi 4-7 Eylül 2002 Erzurum.

Jeppson, L.R., Keifer, H.H., Baker, E.W., 1975. Mites injurious to economic plants. University of California Press, pp.710.

Kasap, İ., 2014. Çanakkale ili bağ alanlarında görülen önemli zararlı ve yararlı akar ( Acari ) türleri ve bu türlerin popülasyon değişimleri. Türkiye Entomoloji Dergisi, 38(4), 451-458.

Kasap, İ., Çobanoğlu, S., 2007. Mite ( Acari ) fauna in apple orchards of around the Lake Van basin of Turkey. Türkiye Entomoloji Dergisi, 31(2), 97-109.

Kasap, İ., Atlıhan, R., Özgökçe, M.S., Kaydan, M.B., Polat, E., Yarımbatman, A., 2008. Van gölü havzası ceviz bahçelerinde saptanan zararlı akarlar ve bunlar üzerinde 
beslenen avcı türler. YYÜ, Ziraat Fakültesi Tarım Bilimleri Dergisi, 18(2), 99-102.

Kasap, İ., Çobanoğlu, S., 2009. Phytoseiid mites of Hakkâri province, with Typhlodromus (Anthoseius) tamaricis Kolodochka, 1982 (Acari: Phytoseidae), a new record for the predatory mite fauna of Turkey. Turkish Journal of Zoology, 33:301-308.

Kasap, İ., Çobanoğlu, S., Pehlivan, S., Kök, Ş., Baştuğ, G., 2015. Çanakkale ve Balıkesir illeri yumuşak çekirdekli meyve ağaçları ve yabancı otlar üzerinde bulunan bitki zararlısı akar türleri. Bitki Koruma Bülteni, 55(2), 85-94.

Kasap, İ., Çobanoğlu, S., Pehlivan, S., 2013. Çanakkale ve Balıkesir illeri yumuşak çekirdekli meyve ağaçları ve yabanc1 otlar üzerinde bulunan predatör akar türleri. Türkiye Biyolojik Mücadele Dergisi, 4(2), 109-123.

Khanjani, M., Hajizadeh, J., Dogh-Abadi, H.Z., 2015. A new species of Agistemus ( Acari : Stigmaeidae ) as a predatory agent of eriophyid mites in olive orchards in Guilan , Iran. Persian Journal of Acarology, 4(1), 1-10.

Kılıç, M., Aykaç, M., 1989. Karadeniz bölgesi şeftali bahçelerindeki zararlilarla mücadelenin yönetimi üzerinde araştirmalar. Bitki Koruma Bülteni, 29(3-4), 211-241.

Knop, N.F., Hoy, M., 1983. Biology of a tydeid mite, Homeopronematus anconai (n. Comb.) (Acari: Tydeidae), important in San Joaquin Valley vineyards. Hilgardia, 51(5), 1-30.

Krantz, G.W., Walter, D.E., 2009. A manual of Acarology, 3rd Editio. Texas Tech University Press, Lubbock pp.807.

Kumral, N.A., Çobanoğlu, S., 2015a. A reservoir weed for mites: Daturastramonium L. (Solanaceae) in the vicinity of cultivated solanaceous plants in Turkey. International Journal of Acarology, 41(7),563-573

Kumral, N.A., Çobanoğlu, S., 2015b. The potential of the nightshade plants (Solanaceae) as reservoir plants for pest and predatory mites. Turkish Journal of Entomology, 39(1),91-108.

Kumral, N.A., Kovanc1, B., 2007. The diversity and abundance of mites in agrochemical-free and conventional deciduous fruit orchards of Bursa , Turkey. Türkiye Entomoloji Dergisi, 31(2),83-95.

Kutlu, S., 2016. Edirne ili sebze alanlarında bulunan fitofag ve predatör akar türlerinin belirlenmesi. Yüksek Lisans Tezi, Namık Kemal Üniversitesi Fen Bilimleri Enstitüsü, 81s, Tekirdağ.

Li H.S., Xue X.F., Hong X.Y., 2012. Eriophyoid mites from Qinghai Province, northwestern China with descriptions of nine new species (Acari, Eriophyoidea). Zookeys, 196:47107.

Madanlar, N., Kısmalı, S., 1991. İzmir ilinde turunçgillerde bulunan Acarina türleri ve popülasyon yoğunluklarının saptanması üzerinde araştırmalar. Doktora Tezi, Ege Üniversitesi Fen Bilimleri Enstitüsü, 258s, İzmir.

Migeon. A., Nouguier, E., Dorkeld, F., 2011. Spider Mites Web: A comprehensive database for the Tetranychidae. inside: Sabelis MW, Bruin J (ed) Trends in Acarology. pp. $557-560$.

Mladenovic, K., Stojnic, B., Vidovic, B., Radulovic, Z., 2013. New records of the tribe Bryobiini berlsese (Acari: Tetranychidae: Bryobiinae) from Serbia, with notes about associated predators (Acari: Phytoseiidae). Archives of Biological Sciences, 65(3),1199-1210.

Montes, S., Raga, A., Boliani, A., Boliani, A.C., de Carvalho Mineiro, J.L., dos Santos, P.C., 2011. Effect of fungicides on the mite fauna of Prunus persica L. cultivars in Presidente Prudente, SP, Brazil. Journal of Plant Protection Research, 51(3), 285-293.
Muma, M.H., Denmark, H.A., 1970. "Phytoseiidae of Florida" arthropods of Florida and neigboring land areas. Florida Department of Agriculture, Division of Plant Industries, (6), 1-150.

Nas, S., Güler, P.G., 2015. Turunçgillerin çiçek ve küçük meyve dönemlerinde bazı akar ve fungus türlerinin belirlenmesi. Harran Tarım ve Gida Bilimleri Dergisi, 19(1), 47-53.

Önuçar, A., Ulu, O., 1988. Kestane ağaçlarında bulunan akar türleri hakkında kısa bilgiler. Türkiye Entomoloji Dergisi. 12(1), 33-38.

Özcan, R., 2007. Başyayla (Karaman) ilçesinde kiraz ağaçlarında bulunan zararlı böcekler, akarlar ve doğal düşmanlarının tespiti üzerine araştırmalar. Yüksek Lisans Tezi, Selçuk Üniversitesi Fen Bilimleri Enstitüsü, 52s, Konya.

Özçağıran, R., Ünal, A., Özeker, E., İsfendiyaroğlu, M., 2003. Ilıman iklim meyve türleri. İçinde: Sert Çekirdekli Meyveler Cilt-I, 553. edn. Ege Üniversitesi Ziraat Fakültesi Yayınları, İzmir, s 229.

Özkan, C., Gürkan, O., Hancıoğlu, Ö., 2005. Çubuk (Ankara) ilçesi vişne ağaçlarında zararli olan türler, doğal düşmanları ve önemlileri üzerinde gözlemler. Tarım Bilimleri Dergisi, 11(1), 57-59.

Özman, S.K., Çobanoğlu, S., 2001. Current status of hazelnut mites in Turkey. Acta Horticulture, 556, 479-488.

Özman-Sullivan, S.K., Kazmierski, A., Çobanoğlu, S., 2005. Alycina and Eupodina mites of hazelnut orchards in Turkey. VI. International Hazelnut Congress, 14-18 June 2004, Tarragona, Spain, Acta Horticulturae, 686: 401-406.

Özman-Sullivan, S.K., Öcal, H., Mıcık, M., 2007. Occurence of mite species in tea plantations in Turkey. XVI International Plant Protection Congress, 2007 October 15-18; Glasgow, Scotland, UK, 2, 764-765.

Özsayın, N., 2012. Kelkit vadisinde(Giresun, Sivas) yer alan bazı ilçelerde yumuşak çekirdekli meyveler üzerindeki akar türleri. Yüksek Lisans Tezi, Gaziosmanpaşa Üniversitesi Fen Bilimleri Enstitüsü, 86s, Tokat.

Özsisli, T., Çobanoğlu, S., 2011. Mite (Acari) fauna of some cultivated plants from Kahramanmaraş, Turkey. African Journal of Biotechnology, 10(11), 2149-2155.

Öztürk, N., Ulusoy, M.R., 2003. Mersin ili kayısılarında saptanan zararlilar. Alatarım, 2(2), 21-26.

Panou, H.N., Emmanouel, N.G., 1996. Two new species of Lorryia (Acari: Prostigmata) from Greece. Mitteilungen aus dem Zoologischen Museum (Hamburg), 12, 91-103.

Pritchard, A.E., Baker, E.W., 1955. A revision of the spider mites family Tetranychidae. San Francisco, Pacific Coast Entomological Society, pp.472.

Riahi, E., Nemati, A., Shishehbor, P., Saeidi, Z., 2011. Population growth parameters of the two-spotted spider mite, Tetranychus urticae, on three peach varieties, in Iran. Acarologia, 51(4), 473-480.

Ripka, G., Fain, A., Kazmierski, A., Kreiter, S., Magowski, W.L., 2002. Recent data to the knowledge of the arboreal mite fauna in Hungary (Acari: Mesostigmata, Prostigmata, and Astigmata). Acarologia, 3:271-281.

Ripka, G., Laniecka, I., Kazmierski, A., 2013. On the arboreal acarofauna of Hungary: Some new and rare species of prostigmatic mites (Acari: Prostigmata: Tydeidae, Iolinidae and Stigmaeidae). Zootaxa, 3702(1), 1-50.

Rowell, H.J., Chant, D.A., Hansell, R.I.C., 1978. The determination of setal homologies and setal patterns on the dorsal shield in the family Phytoseiidae (Acarina: Mesostigmata). Canadian Journal of Zoology, 110, 859876. 
Sağlam, H.D., Çobanoğlu, S., 2010. Determination of Tenuipalpidae (Acari: Prostigmata) species in parks and ornamental plants of Ankara, Turkey. Türkiye Entomoloji Dergisi. 34, 37-52.

Satar, S., Ada, M., Kasap, İ., Çobanoğlu, S., 2013. Acarina fauna of citrus trees in eastern Mediterranean region of Turkey. Integrated Control in Citrus Fruit Crops IOBCWPRS Bulletin, 95:171-178.

Seeman, O.D., Beard, J.J., 2011. Identification of exotic pest and Australian native and naturalised species of Tetranychus (Acari: Tetranychidae). Zootaxa, 2961, 1-72.

Shinkaji, N., 1979. Geographical distribution of the citrus red mite, Panonychus citri and european red mite, P. ulmi in Japan. inside: Recent Advances in Acarology, Vol I. pp. 81-87.

Skvarla, M., Fisher, J., Dowling, A., 2014. A review of Cunaxidae (Acariformes, Trombidiformes): histories and diagnoses of subfamilies and genera, keys to world species, and some new locality records. Zookeys, 418:1-103.

Smith Meyer, M.K.P., Craemer, C., 1999. Mites (Arachnida: Acari) as crop pests in southern Africa: an overview. African Plant Protection, 5(1), 37-51.

Soysal, M., 2017. Ordu ilinde yetiştirilen bazı sebzelerde bulunan faydalı ve zararlı akar türlerinin belirlenmesi. Yüksek Lisans Tezi, Ordu Üniversitesi Fen Bilimleri Enstitüsü, 233s, Ordu.

Soysal, M., Akyazı, R., 2018. Mite species of the vegetable crops in Ordu Province with first reportof Amblyseius rademacheri Dosse, 1958 (Mesostigmata:Phytoseiidae) in Turkey.Turkish Journal of Entomology, 42 (4): 265-286.

Solarz K., 2012. House dust mites and storage mites (Acari: Oribatida: Astigmatina). identification keys. Institute of systematics and evolution of animals, Polish Academy of Sciences, Cracow, Poland, 120pp.

Stojnic, B., Panou, H., Papadoulis, G., Petanovic, R., Emmanouel, N., 2002. The present knowledge and new records of Phytoseiid and Tydeid mites (Acari: Phytoseiidae, Tydeidae) for the fauna of Serbia and Montenegro. Acta Entomologica Serbica, 7(1-2), 111-117.

Swirski, E., Amitai, S., 1982. Notes on predacious mites (Acarina: Phytoseiidae) from Turkey, with description of the male of Phytoseius echinus Wainstein and Arutunian. Israel Journal of Entomology, 16:55-62.

Şekeroglu, E., Kazak, C., 1993. First record of Phytoseiulus persimilis (Acari: Phytoseiidae) in Turkey. Entomophaga, 38(3), 343-345.

Tempfli, B., Pénzes, B., Fail, J., Szabó, A., 2015. The occurrence of tydeoid mites (Acari: Tydeoidea) in
Hungarian vineyards. Systematic and Applied Acarology, 20(8), 937-954.

Tokkamış, F., 2011. Tokat ilinde yetiştirilen bazı sebze türlerinde faydalı ve zararlı akar (Acari) türlerinin belirlenmesi. Yüksek Lisans Tezi, Gaziosmanpaşa Üniversitesi, Fen Bilimleri Enstitüsü, 59s, Tokat.

Toros, S., 1974. Orta Anadolu bölgesinde önemli bitki zararlılarından Tetranychus viennensis Zacher (Akdiken Akarı)'in morfolojisi, biyolojisi, yayilişi ve konukçuları ile kimyasal savaş imkanları üzerine araştırmalar. Ankara Üniversitesi Ziraat Fakültesi Yayınları, 514,74.

TÜIK, 2017. Bitkisel üretim istatistikleri veri tabani. https://biruni.tuik.gov.tr/medas/?kn=92\&locale=tr (Erişim tarihi: 20 Nisan 2018).

Ueckermann, E.A., Çobanoğlu, S., 2012. Phytophagous mites of economical importance of Turkey, Workshop in Taxonomic Acarology, 21-22/06/2012, Ankara, s: 61.

Ueckermann, E.A., 2013. Course on taksonomy of the Tydeoidae, 24pp.

Ulusoy, M.R., Vatansever, G., Uygun, N., 1999. Ulukışla (Niğde) ve Pozantı (Adana) yöresi kiraz ağaçlarında zararlı olan türler, doğal düşmanları ve önemlileri üzerindeki gözlemler. Türkiye Entomoloji Dergisi, 23(2),111-120.

Yanar, D., Ecevit, O., 2005. Tokat ilinde elma (Malus communis L.) bahçelerinde görülen bitki zararlisi ve predatör akar türleri. Ondokuz Mayıs Üniversitesi Ziraat Fakültesi Dergisi, 20(1), 18-23.

Yarpuzlu, F., Öztemiz, S., Karacaoğlu, M., 2008. Natural enemies and population movement of the California red scale, Aonidiella aurantii maskell (Homoptera: Diaspididae) with efficiency of parasitoid, Aphytis melinus (How.) (Hymenoptera: Aphelinidae) in lemon orchards. Journal of the Entomological Research Society, 10(1), 4358.

Yeşilayer, A., Çobanoğlu, S., 2011. The distribution of predatory mite species (Acari : Phytoseiidae) on ornamental plants and parks of Istanbul, Turkey. Türkiye Entomoloji Dergisi, 1(3), 135-143.

Yeşilayer, A., Uçar, M.H., 2016. Phytoseiid mites on ornamental plants in Tokat. American Journal of Engineering Research (AJER), 5(10), 354-357.

Zhang, Z., Henderson, R., Flynn, A., Martin, N.A., 2002. Key to Tetranychidae of New Zealand. Landcare Research Contract Report: LC0102/144, Prepared for: MAF Science Policy, Project FMA180, 62pp.

Zhang, Z.Q., 2003. Mites of greenhouses identification, biology and control. CABI Publishing, 244pp. 